\title{
MicroRNAs - important molecules in lung cancer research
}

\author{
Petra Leidinger $^{1}$, Andreas Keller ${ }^{1,2}$ and Eckart Meese ${ }^{1 *}$ \\ Institute of Human Genetics, Medical School, Saarland University, Homburg, Germany \\ ${ }^{2}$ Siemens Healthcare, Erlangen, Germany
}

\section{Edited by:}

Ashish Lal, National Institutes of

Health, USA

Reviewed by:

Nhan Le Tran, Translational Genomics

Research Institute, USA

Roopa Biswas, Uniformed Services

University of Health Sciences, USA

Derek Michael Dykxhoorn, University of Miami Miller School of Medicine,

USA

*Correspondence:

Eckart Meese, Institute of Human

Genetics, Medical School, Saarland

University, Kirrbergerstrasse, Building

60, 66421 Homburg, Germany.

e-mail:hgemee@uks.eu
MicroRNAs (miRNA) are important regulators of gene expression. They are involved in many physiological processes ensuring the cellular homeostasis of human cells. Alterations of the miRNA expression have increasingly been associated with pathophysiologic changes of cancer cells making miRNAs currently to one of the most analyzed molecules in cancer research. Here, we provide an overview of miRNAs in lung cancer. Specifically, we address biological functions of miRNAs in lung cancer cells, miRNA signatures generated from tumor tissue and from patients' body fluids, the potential of miRNAs as diagnostic and prognostic biomarker for lung cancer, and its role as therapeutic target.

Keywords: microRNA, lung cancer, body fluids, blood, biomarker, diagnosis, prognosis, therapy

\section{INTRODUCTION}

Besides housekeeping genes, the expression of all other genes is mostly regulated through a complex mechanism that enables a cell type specific and time specific expression. Regulations can occur during each step of gene expression, e.g., during chromatin remodeling, transcription and translation, RNA transport, or on the post-transcriptional level. The main gene expression regulators are proteins or enzymes, e.g., histones, transcription factors, and polymerases. Gene expression can also be regulated by antisense or sense nucleic acids (Helene and Toulme, 1990). MicroRNAs (miRNAs) are a highly conserved family of small RNAs (17-22 nt) that regulate the expression of their target genes usually on the posttranscriptional level by binding to complementary sequences on target messenger RNA transcripts (mRNAs) mostly resulting in gene silencing. Since the first description of miRNAs in 1993 by Victor Ambros, Rosalind Lee, and Rhonda Feinbaum in C. elegans (Lee et al., 1993) more than 1500 different human miRNAs (see miRBase V18, http://www.mirbase.org) have already been identified. As each miRNA can regulate hundreds of target genes, it is assumed that the majority of the 20,000-25,000 human genes may be regulated by specific miRNAs (van Kouwenhove et al., 2011). Silencing of the target genes is obviously the main regulation mechanism - either by translational repression or by mRNA degradation. Perfect matching of the miRNA to the $3^{\prime}$ UTR of its target mRNA results in direct mRNA degradation whereas imperfect matching - with nucleotides 2-7 of the miRNA (called "seed region") still perfectly complementary - leads to translational repression. Bartel and colleagues analyzed the relative contribution of these two outcomes and found that degradation of the mRNA by miRNAs is with more than $80 \%$ of cases the predominant reason for a reduced protein output (Guo et al., 2010). Recently, miRNAs were also shown to up-regulate target gene expression either directly through binding to the target mRNA (Vasudevan et al., 2007) or indirectly through repressing nonsense-mediated RNA decay (Bruno et al., 2011). According to their function miRNAs play an essential role in cellular processes as development, proliferation, and apoptosis ensuring the cellular homeostasis of healthy human cells. An alteration of this cellular homeostasis through aberrant expression of miRNAs likely contributes to many human pathologies including cancer. Calin et al. (2002) revealed for the first time a possible correlation between miRNA deregulation and cancer. Subsequently, a multitude of studies about miRNA expression changes and cancer has been reported.

Lung cancer is worldwide the leading cause of cancer related deaths. The 5 -year overall survival rate strongly correlates with the time of diagnosis and varies between 60 and $80 \%$ in clinical stage I to only $1 \%$ in clinical stage IV. Unfortunately, lung cancer is mostly diagnosed in late stages. Currently, no appropriate biomarker exists to detect lung cancer at early stages. Takamizawa et al. (2004) were the first to relate miRNA expression to lung cancer. Since then the number of publications dealing with the relation between miRNA expression and lung cancer has raised to above 400 .

In this review we place emphasis on the current status of miRNA research in lung cancer. Specifically, we focus on current findings on the molecular role of miRNAs in lung cancer development and progression. In addition, we address the potential of miRNA research for tumor diagnosis and therapy.

\section{DETECTION OF miRNAs IN HUMAN SAMPLES}

Most of the miRNA expression data have been generated by the analysis of tissue samples with the main focus on cancer tissue. The data collected from tissue samples may provide the best insights into the involvement of miRNAs in a disease state. As miRNAs are markedly stable against degradation, stored formalin-fixed paraffin embedded (FFPE) tissue can be used for miRNA isolation (Liu 
and $\mathrm{Xu}, 2011)$. Lu et al. (2005) showed that tissue miRNA expression profiles are highly cell type specific and that they reflect the developmental lineage and the differentiation state. MiRNA expression data derived from 40 different tissue samples from healthy individuals revealed both a group of universally expressed miRNAs and groups of tissue specific expressed miRNAs (Liang et al., 2007). Besides tissues, sources for miRNAs can be body fluids such as whole blood, serum, plasma, urine, cerebrospinal fluid (CSF), and - especially in the case of lung cancer research saliva, sputum, or bronchoalveolar lavage (BAL) (Weber et al., 2010; Tzimagiorgis et al., 2011). MiRNA profiles of body fluids are useful for the analysis of disease states especially when the disease does not originate from one distinct type of cell and when the tissue is not readily accessible, e.g., in neurological disorders (e.g., Schizophrenia, Lai et al., 2011; Alzheimer's Disease, Schipper et al., 2007), in heart failure (Voellenkle et al., 2010; Meder et al., 2011), in autoimmune diseases (e.g., Lupus, Wang et al., 2011), and in respiratory tract diseases (e.g., COPD, Pottelberge et al., 2011). In general, miRNA profiles of body fluids, including urine (Hanke et al., 2010), serum (Mitchell et al., 2008; Otaegui et al., 2009), saliva (Park et al., 2009), sputum (Xing et al., 2010), CSF (Baraniskin et al., 2011) have been discussed as future noninvasive biomarkers. How miRNAs enter the body fluids is still a largely unsolved question. One possibility is that cancer cells without metastatic potential enter the blood stream and release their cell content including miRNAs after passing through a suicide program (Mehes et al., 2001). Alternatively, miRNAs packed in microvesicles or exosomes are actively released in the bloodstream (Hunter et al., 2008; Rabinowits et al., 2009). Notably, miRNAs measured in body fluids frequently reflect different cell types. For example, urine of a bladder cancer patient contains apoptotic or necrotic cells, non-malignant exfoliated urothelial cells, and leukocytes besides tumor cells (Hanke et al., 2010), all of which may contribute to the miRNA expression profile. Saliva contains blood cells, microorganisms, and apoptotic or detached living epithelial cells. Cell-free nucleic acids actively released by cancer and epithelial cells or inactively by apoptotic cells and micro-wounds have also been found in saliva (Park et al., 2006). Likewise, different cell types contribute to miRNA profiles in sputum (Thunnissen, 2003; Xie et al., 2010; Yu et al., 2010), BAL (Ahrendt et al., 1999; Schmidt et al., 2005), and CSF (Karlsson et al., 2001; Reiber and Peter, 2001).

In conclusion, the measurement of miRNAs in body fluid has high potential for future non-invasive diagnostic tests especially for cancer. There are, however, various hurdles to be overcome to turn a miRNA signature into a diagnostic tool. Among others, the amount of specific miRNAs may be limited in certain body fluids, the availability of body fluid may also be limited, standardized protocols have not yet been established for the isolation and analysis of RNA from body fluids, and detection methods have to be optimized. As for the latter, microarray experiments are both cost-intensive and time-consuming while qRT-PCR lacks reliable endogenous controls for body fluids.

\section{THE MOLECULAR BIOLOGY OF miRNAs IN LUNG CANCER}

The first aberrantly expressed miRNA in lung cancer was identified in 2004 (Takamizawa et al., 2004). By analyzing 143 potentially curative resected lung cancer samples Takamizawa et al. (2004) showed that a reduced let-7 expression is correlated with a shorter post-operative survival. They confirmed their results by introducing let-7 into the adenocarcinoma cell line A549. The observed overexpression resulted in growth inhibition of the cells. These findings laid the basis for further studies on the molecular mechanisms of the tumor suppressor function of let-7. The $3^{\prime}$ UTR of HRAS, KRAS, and NRAS that are members of the RAS GTPase family, contain multiple putative let-7 binding sites. The expression of let-7 in lung cancer was inversely correlated to RAS expression. On the basis of these results Johnson et al. (2005) concluded that let-7 is a negative regulator of the oncogene RAS. Microarray analysis revealed additional genes whose expressions were altered in the presence of excess let-7 (Johnson et al., 2007). These genes include key cell cycle proto-oncogenes such as CDC25a, CDK16, and cyclin D that are involved in the G1/S transition. These findings gave further support to the assumption that let-7 functions as tumor suppressor miRNA. Recently, let-7 was shown to target BCL-2, thereby inhibiting the growth of A549 cells (Xiong et al., 2011). As BCL-2 is a proto-oncogene involved in regulation of apoptosis, a negative regulation through let-7 may result in growth suppression and apoptosis induction of A549 cells. Esquela-Kerscher et al. (2008) confirmed that let-7 reduces in vivo tumor growth of lung cancer cell xenografts in immunodeficient mice.

Hayashita et al. (2005) found an overexpressed intronic miRNA cluster (miR-17-92) encompassing seven different miRNAs namely hsa-miR-17-5p, hsa-miR-17-3p, hsa-miR-18a, hsamiR-19a, hsa-miR-19b-1, hsa-miR-20a, and hsa-miR-92 in the amplified chromosomal region $13 q 31.3$ in lung cancer, mostly in small cell lung cancer. This polycistronic miRNA cluster was first described by He et al. (2005) in B-cell lymphomas. Antisense oligonucleotides against mir-17-5p and miR-20a were shown to induce apoptosis in mir-17-92 overexpressing lung cancer cells (Matsubara et al., 2007). Recently, Kanzaki et al. (2011) were able to identify several direct targets of the miR-17-92 oncogene. A summary of the various roles of the miR-17-92 cluster was given by Joshua T. Mendell in Cell (Mendell, 2008).

Besides hsa-let-7 and the miRNAs of the miR-17-92 cluster, there are numerous reports on other miRNAs that are deregulated in lung cancer tissue, e.g., hsa-miR-21 whose overexpression was suggested to be an independent negative prognostic factor for the overall survival in NSCLC patients (Markou et al., 2008; Gao et al., 2010). Hsa-miR-21 targets tumor suppressor genes such as programmed cell death 4 (Pdcd4; Lu et al., 2008) and PTEN (Zhang et al., 2010). There is evidence that the expression of miRNA-21 is up regulated by epidermal growth factor receptor (EGFR)-signaling in lung cancer (Seike et al., 2009). In 15\% of all lung cancer patients, mostly never-smokers, EGFR contained a mutation resulting in constitutive activation of tyrosine kinase (TK), which in turn leaded to tumor progression (da Cunha Santos et al., 2011). The inhibition of the EGFR signaling by a tyrosine kinase inhibitor (TKI) resulted in a reduced expression of miR-21 (Seike et al., 2009). But, since miR-21 is also deregulated in several other cancer types, it seems to be a general oncogenic miRNA without tissue specificity (Ciafre et al., 2005; Volinia et al., 2006; Iorio et al., 2007; Meng et al., 2007). 


\section{IMPACT OF MIRNA RESEARCH ON CLINICAL ONCOLOGY}

The 5-year survival of lung cancer patients is $15 \%$ for all stages combined. Early detection of lung cancer in high-risk patients is likely to improve the prognosis. Currently, less than $20 \%$ of lung cancer patients are diagnosed with a locally confined tumor (Jemal et al., 2009). This low detection rate calls for the identification of new reliable biomarkers to allow non-invasive early detection of locally confined lung cancers. The markers should also contribute to the distinction between benign and malignant lesions.

MicroRNAs play an essential role in lung development (Tomankova et al., 2010). Due to the different expression pattern in healthy lung tissue compared to lung cancer tissue it seemed legitimate to assume that aberrant miRNA expression may be involved in the onset of lung cancer (Mascaux et al., 2009; Megiorni et al., 2011). By microarray analyses of the miRNA expression in 104 pairs of primary lung cancers and corresponding non-cancerous lung tissues Yanaihara et al. (2006) identified a specific miRNA profile, encompassing 43 differentially expressed miRNAs. Volinia et al. (2006) performed a large-scale analysis of the miRNA profiles of 540 samples, encompassing 363 samples from patients with six different types of solid tumors including lung cancer and 177 normal tissue samples. They identified a cancer miRNA signature with mostly overexpressed miRNAs. Besides the identification of cancer type specific miRNA signatures, research is also aiming at the identification of specific miRNAs that are suited to differentiate between histological lung cancer subclasses. As treatment depends on the histological subtype, such miRNAs are likely to be useful for decision-making in clinical treatment. Lebanony et al. (2009) were able to provide a highly accurate subclassification of NSCLC patients. They identified miR-205 as suitable marker for squamous cell lung carcinoma by comparing the miRNA expression pattern between 122 adenocarcinoma and squamous NSCLC samples (Lebanony et al., 2009). MiRNA signatures also appeared suitable to distinguish SCLC cells from NCLC cells (Du et al., 2010). Vosa et al. (2011) provided evidence for miR-374 as a potential marker for early stage NSCLC. Recently, different groups were able to identify miRNAs that differentiated NSCLC patients with brain metastases from patients without brain metastases (Arora et al., 2011; Nasser et al., 2011). Biomarkers that allow identification of NSCLC patients with increased risk for brain metastases will be of great value for the decision-making in preventive radiation treatment.

As miRNAs are very stable not only in tissue but also in body fluids, they offer themselves as potential biomarker for non-invasive early detection of lung cancer. Especially, for lung cancer the poor survival time and the high relapse rates after surgery call for new methods to detect the disease at early stage. MiRNA expression patterns have also the potential to be a useful prognostic tool. In addition, there is growing interest to use miRNAs as therapeutic agent. Especially the increasing knowledge about the role of miRNAs as tumor suppressors or activators of oncogenes, will help to develop novel miRNA-based therapeutic approaches. Figure 1 provides an overview about potential different clinical applications of miRNAs in oncology. Figure 2 gives an overview of the potential time points for the application of lung cancer specific miRNAs. Table A1 in Appendix provides information on miRNAs associated with lung cancer.

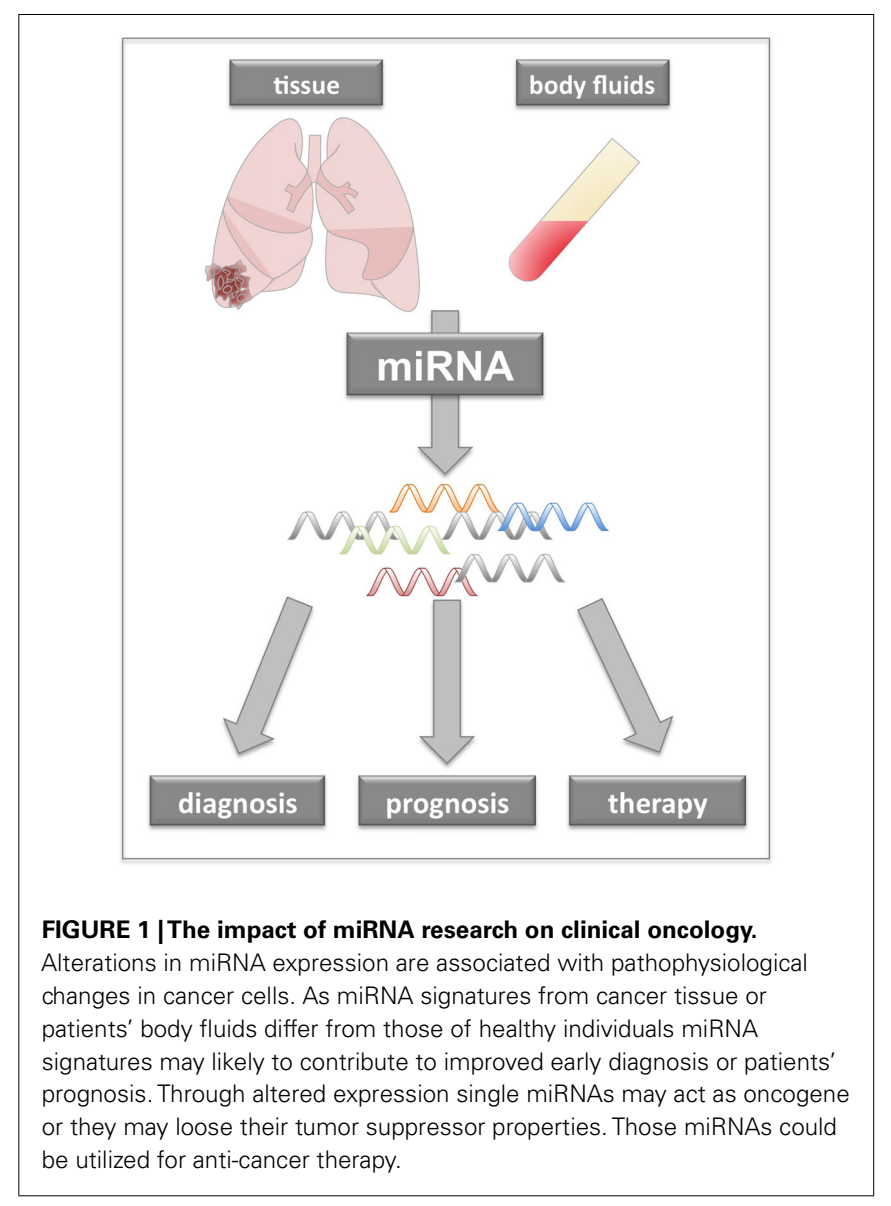

miRNAs AS POTENTIAL DIAGNOSTIC BIOMARKER FOR LUNG CANCER

It is well known that the onset of cancer impacts the immune system leading to changes in the gene expression of blood cells (Pardoll, 2003; Kossenkov et al., 2011). Jeong et al. (2011) showed that the expression of let-7a is reduced not only in lung cancer tissue, but also in blood of lung cancer patients compared to healthy individuals. In our recent studies, we were able to separate blood samples of lung cancer patients from blood samples of healthy individuals by miRNA signatures with a specificity of $98.1 \%$ and a sensitivity of $92.5 \%$ (Keller et al., 2009). In addition we reported miRNA signatures that differentiated blood samples of lung cancer patients from blood samples of patients with non-malignant chronic obstructive pulmonary disease with $89.2 \%$ specificity, and 91.7\% sensitivity (Leidinger et al., 2011). Recently, we showed in a multicenter study that different types of cancer or non-cancer diseases could be differentiated by blood-borne miRNA profiles (Keller et al., 2011a).

As above mentioned, miRNAs are also present in other body fluids. Yu et al. (2010) showed that miRNAs were stably present in sputum. They were able to differentiate lung adenocarcinoma patients from healthy individuals by using a panel of four sputum miRNAs namely miR-486, miR-21, miR-200b, and miR-375, with high sensitivity (80.6\%) and specificity (91.7\%; Yu et al., 2010). The same group identified three sputum miRNAs, namely miR205, miR-210, and miR-708 that distinguished squamous cell lung 


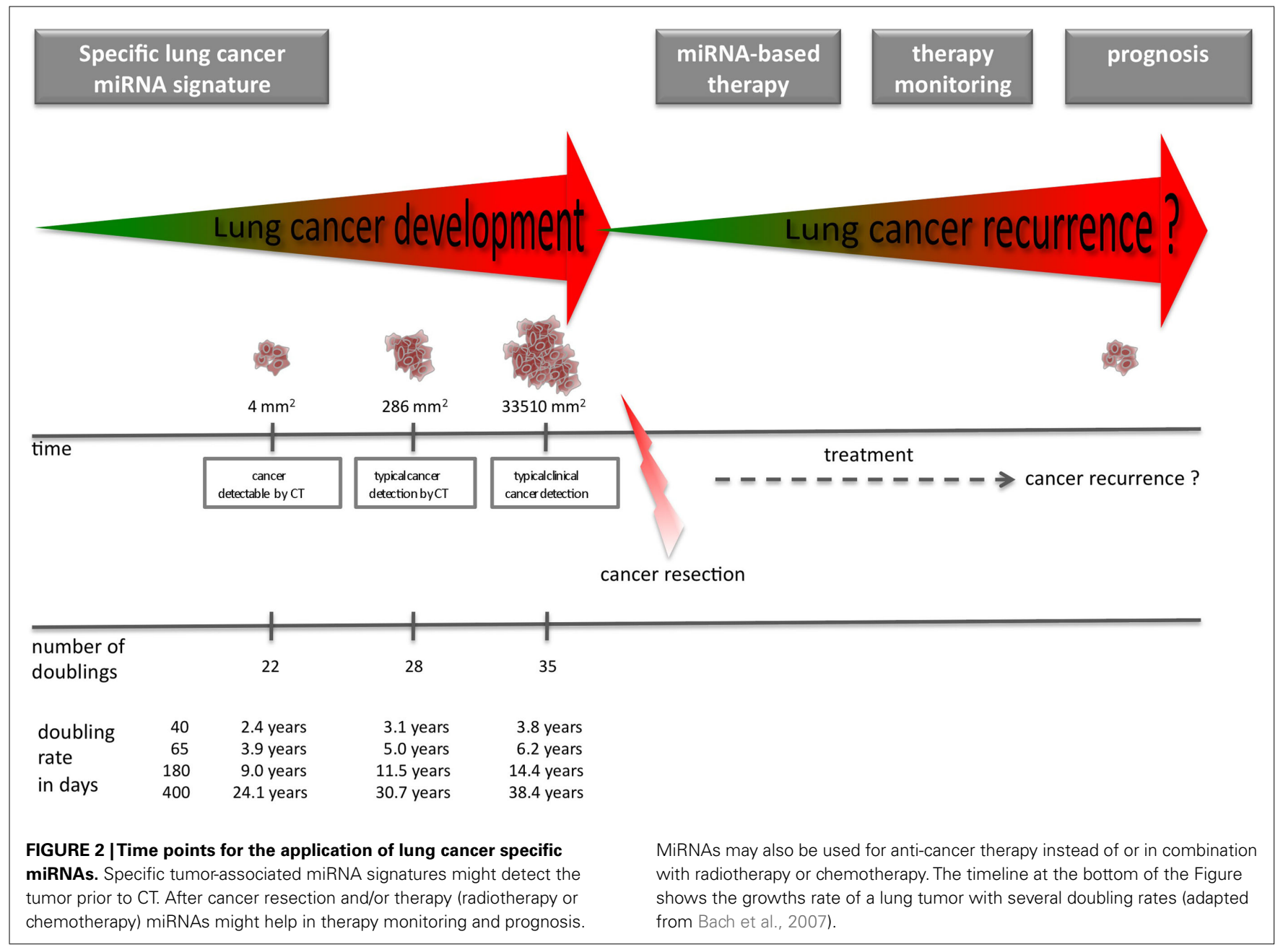

carcinoma patients from healthy individuals with $73 \%$ sensitivity and $96 \%$ specificity (Xing et al., 2010).

Since the first study that demonstrated larger amounts of stable miRNAs in serum and plasma, several studies proved that the serum or plasma miRNAs show great promise as novel noninvasive biomarkers for the early diagnosis of various cancers and other diseases (Chen et al., 2008; Mitchell et al., 2008). Chen et al. (2011) identified in a genome-wide serum miRNA expression study a specific panel of 10 miRNAs that was able to distinguish NSCLC cases from controls with high sensitivity and specificity and that correlated with the stage of NSCLC. Furthermore, this 10-serum miRNA profile could accurately classify serum samples collected up to 3 years prior to the clinical NSCLC diagnosis. By expression analysis of two serum miRNAs (hsa-miR-1254 and hsamiR-574-5p), Foss et al. (2011) were able to discriminate early stage NSCLC samples from controls with a sensitivity of $82 \%$ and a specificity of $77 \%$ in a training cohort and with a sensitivity of $73 \%$ and a specificity of $71 \%$ in a validation cohort. Shen et al. (2011) recently identified a panel of four miRNAs namely miR-21, miR-126, miR-210, and miR-486-5p, that distinguished NSCLC patients from the healthy controls with $86.22 \%$ sensitivity and $96.55 \%$ specificity. Furthermore, the panel of miRNAs identified stage I NSCLC patients with $73.33 \%$ sensitivity and
$96.55 \%$ specificity. Interestingly, two of these miRNAs, namely miR-21 and miR-486, show an overlap with the study on sputum by Yu et al. (2010). Rabinowits et al. (2009) investigated the expression of 12 specific miRNAs including hsa-miR-17-3p, hsa-miR-21, hsa-miR-106a, hsa-miR-146, hsa-miR-155, hsa-miR191, hsa-miR-192, hsa-miR-203, hsa-miR-205, hsa-miR-210, hsamiR-212, and hsa-miR-214, in circulating exosomes. The authors suggest that circulating exosomal miRNA might be useful in a screening test for lung adenocarcinoma. In a recent study, we reported serum miRNA profiles as a non-invasive method to detect lung cancer at an early stage (Keller et al., 2011b). We analyzed miRNA signatures in serum from lung cancer patient samples, which were collected prior and after diagnosis. We found that most obvious changes in miRNA expression profiles occur at a time close to diagnosis possibly indicating increased tumor development. Likewise, Boeri et al. (2011) were able to predict lung cancer in plasma samples $1-2$ years prior to diagnosis using CT. For the time being, however, the source of circulating miRNAs is elusive. As indicated above it has been suggested that they are released due to apoptosis or active exocytosis processes (Kosaka et al., 2010). This hypothesis is supported by the study by Rabinowits et al. (2009) that showed a similarity between the circulating exosomal miRNA and the lung tumor-derived miRNA patterns. In contrast, 
miRNAs deregulated in lung cancer tissue were rarely detected in plasma samples from lung cancer patients in the study of Boeri et al. (2011) that compared the expression of deregulated miRNAs in lung cancer tissue with the expression in plasma specimens. To draw further conclusions about the relationship between miRNA profiles in body fluids and the tumor, more insight is required into both the exact role of miRNAs as molecular regulators in tumor cells and the mechanisms underlying the release of miRNA into body fluids.

\section{miRNAs AS POTENTIAL PROGNOSTIC BIOMARKER FOR LUNG CANCER}

Various up- and downregulated miRNAs have been associated with patients' survival. Vosa et al. (2011) showed that low expression of miR-374 could be associated with patients' low survival time. Yanaihara et al. (2006) demonstrated that high expression of hsa-miR-155 and low expression of hsa-let-7a-2 were associated with lung cancer patients' poor survival time. Raponi et al. (2009) showed that miR-146b was associated with reduced survival time in squamous cell carcinoma tissues (SCC). Recently, a study by Landi et al. (2010) presented a miRNA signature including let-7e, miR-34a, miR-34c-5p, miR-25, and miR-191, which was associated with a prognosis of poor survival among male smokers suffering from stage I to IIIa SCC. A miR-21 overexpression in NSCLC that was detected by Markou et al. (2008) has been suggested as future negative prognostic factor. Hu et al. (2010) analyzed miRNA expression profiles in sera of 303 patients with stage I to IIIA NSCLC. They detected miRNA levels altered between patients with shorter survival and longer survival time. Moreover, their results revealed that four miRNAs, including miR-486, miR-30d, miR-1, and miR-499 correlated with overall survival. Furthermore, increased levels of miR-25 and miR-223 in serum may in the future serve as potential markers for NSCLC (Chen et al., 2008). By using microarray, Liu et al. (2011) analyzed the miRNA expression of six paired lung cancer and normal tissues and identified three differentially expressed miRNAs namely miR-21, miR-141, and miR-200c. High expressions of miR-21 and miR-200c in the tumor and of miR-21 in serum were associated with a poor survival in NSCLC patients (Liu et al., 2011).

Although the above studies clearly show that miRNA expression can be associated with patients' survival, the specific miRNAs associated with patient survival differ substantially between studies. These discrepancies are due to (i) different sources of miRNA, i.e., tissue or body fluid, (ii) different methods applied for miRNA analysis, i.e., microarray, qRT-PCR, and deep sequencing, (iii) varying numbers of analyzed miRNAs, and (iv) the criteria used to select patient cohorts, i.e., ethnicity, clinicopathologic features, and therapy. Future studies of miRNA signatures should benefit from largely standardized protocols.

\section{miRNAs AS POTENTIAL THERAPEUTIC AGENT}

An increasing number of studies examined the therapeutic potential of miRNAs. Major emphasis is given to the analysis of hsalet-7, which was the first miRNA associated with lung cancer development (Takamizawa et al., 2004; Johnson et al., 2005, 2007). Exogenous delivery of let-7 inhibited lung cancer growth both in mouse models and in human lung cancer cell lines (EsquelaKerscher et al., 2008; Trang et al., 2010). As for the therapeutic potential of other miRNAs, a very recent study by Frezzetti et al. (2011) showed that upregulation of miR-21 is controlled by the oncogene RAS and that a locked nucleic acid (LNA) against miR21 decelerates tumor growth in mice. MiRNA-145 that is known to function as tumor suppressor in several types of cancer (Akao et al., 2007; Porkka et al., 2007; Nam et al., 2008) was recently shown to inhibit cell proliferation in NSCLC cells. Specifically, exogenous miRNA-145 inhibited cell proliferation in NSCLC cells by targeting Myc (Chen et al., 2010). MiR-93, miR-98, and miR197 all of which are overexpressed in lung cancer, interact with the $3^{\prime}$ UTR of the tumor suppressor gene FUS1. This interaction results in a downregulation of the protein expression making these miRNAs crucial for tumor progression (Du et al., 2009). MiR-128b was shown to directly regulate EGFR in NSCLC cell lines. In addition, loss of heterozygosity of miR-128b was associated with both the clinical response and patients' survival (Weiss et al., 2008). Overexpression of miR-192, which is weakly expressed in lung cancer, resulted in decreased retinoblastoma 1 ( $r b 1)$ mRNA and $\mathrm{Rb} 1$ protein expression. These data indicate that miR-192 induces cell apoptosis through the caspase pathway (Feng et al., 2011).

To fully benefit from the large number of miRNAs and their potential targets, computational algorithms like PicTar, miRanda, and Target Scan have been developed to detect adequate miRNA targets (Sethupathy et al., 2006; Backes et al., 2010). In addition, suitable delivery systems are being developed to transport miRNAs or antagomirs - specific oligomers used as miRNA antagonists - to their potential targets (Landen et al., 2005; Shahzad et al., 2011). Antagomirs have been shown to reduce levels of corresponding miRNAs in vivo (Krutzfeldt et al., 2005). Using a lipid-based delivery system and chemically synthesized miR-34a, Wiggins et al. (2010) demonstrated growth inhibition of subcutaneous NSCLC cells in mice. The same group used this delivery system in Kras-activated autochthonous mouse models of NSCLC. They found that systemic application of complexes consisting of synthetic miRNA-mimics for let-7 and miR-34a and of the neutral lipid emulsion are preferentially directed to tumor sites and significantly decreased tumor burden (Trang et al., 2011). Most recently, a cationic lipid-based miRNA system was used to condense miRNA miR-133b to form lipoplexes in order to enhance cellular uptake and pharmacological effectiveness in vitro and in vivo (Wu et al., 2011). As a tumor suppressor that directly targets the pro-survival gene MCL-1, hsa-miR-133b seems to be a potential therapeutic target to influence both cell survival and sensitivity of lung cancer cells to chemotherapeutic agents (Wu et al., 2011). Although these examples underline the therapeutic perspectives of miRNAs, several challenges have to be addressed on the road toward clinical application. First, delivery systems without toxic side effects are required to effectively and selectively transport miRNA-based therapeutics to the tumor site. As of now, lipid-based carrier (Wiggins et al., 2010), nanoparticles (Shi et al., 2011) or viral delivery systems (Zhang et al., 2006), have in vitro or in vivo been investigated for cancer therapy. Second, the ability of a single miRNA to regulate of up to several 100 targets genes complicates specific targeting and might readily result in unspecific effects. For further information on the therapeutic potential of miRNAs we would like to refer the reader to the reviews of Kasinski and Slack (2011) in Nature Reviews 
and McDermott et al. (2011) in Pharmaceutical Research, which provide a comprehensive summary of the current in vivo and/or in vitro studies.

\section{CONCLUSION}

Since their discovery in the 1990s miRNAs have increasingly been recognized as significant not only for the understanding of cancer growth and progression, but also as potential cancer biomarkers. Lung cancer as a disease with poor prognosis and a death toll of thousands of cases per year is one of the prime cancers that call for new markers to allowing early diagnosis. As summarized there is considerable progress in developing miRNA signatures into new biomarkers for lung cancer. MiRNA signatures are likely to contribute to improved early diagnosis, patients' prognosis, or anti-cancer therapy. It is to be, however, recognized, that the

\section{REFERENCES}

Ahrendt, S. A., Chow, J. T., Xu, L. H., Yang, S. C., Eisenberger, C. F., Esteller, M., Herman, J. G., Wu, L., Decker, P. A., Jen, J., and Sidransky, D. (1999). Molecular detection of tumor cells in bronchoalveolar lavage fluid from patients with early stage lung cancer. J. Natl. Cancer Inst. 91, 332-339.

Akao, Y., Nakagawa, Y., and Naoe, T. (2007). MicroRNA-143 and -145 in colon cancer. DNA Cell Biol. 26, 311-320.

Arora, S., Ranade, A. R., Tran, N. L., Nasser, S., Sridhar, S., Korn, R. L., Ross, J. T., Dhruv, H., Foss, K. M., Sibenaller, Z., Ryken, T., Gotway, M. B., Kim, S., and Weiss, G. J. (2011). MicroRNA-328 is associated with (non-small) cell lung cancer (NSCLC) brain metastasis and mediates NSCLC migration. Int. J. Cancer 129, 2621-2631.

Bach, P. B., Silvestri, G. A., Hanger, M., and Jett, J. R. (2007). Screening for lung cancer: ACCP evidence-based clinical practice guidelines (2nd edition). Chest 132(Suppl. 3), 69S-77S.

Backes, C., Meese, E., Lenhof, H. P., and Keller, A. (2010). A dictionary on microRNAs and their putative target pathways. Nucleic Acids Res. 38, 4476-4486.

Baraniskin, A., Kuhnhenn, J., Schlegel, U., Chan, A., Deckert, M., Gold, R., Maghnouj, A., Zollner, H., Reinacher-Schick, A., Schmiegel, W., Hahn, S. A., and Schroers, R. (2011). Identification of microRNAs in the cerebrospinal fluid as marker for primary diffuse large B-cell lymphoma of the central nervous system. Blood 117, 3140-3146.

Boeri, M., Verri, C., Conte, D., Roz, L., Modena, P., Facchinetti, F., Calabro, E., Croce, C. M., Pastorino, U., and Sozzi, G. (2011). MicroRNA signatures in tissues and plasma predict development and prognosis of computed tomography detected lung cancer. Proc. Natl. Acad. Sci. U.S.A. 108, 3713-3718.

Bruno, I. G., Karam, R., Huang, L., Bhardwaj, A., Lou, C. H., Shum, E. Y., Song, H. W., Corbett, M. A., Gifford, W. D., Gecz, J., Pfaff, S. L., and Wilkinson, M. F. (2011). Identification of a microRNA that activates gene expression by repressing nonsense-mediated RNA decay. Mol. Cell 42, 500-510.

Calin, G. A., Dumitru, C. D., Shimizu, M., Bichi, R., Zupo, S., Noch, E., Aldler, H., Rattan, S., Keating, M., Rai, K., Rassenti, L., Kipps, T., Negrini, M., Bullrich, F., and Croce, C. M. (2002). Frequent deletions and down-regulation of micro- RNA genes miR15 and miR16 at 13q14 in chronic lymphocytic leukemia. Proc. Natl. Acad. Sci. U.S.A. 99, 15524-15529.

Chen, X., Ba, Y., Ma, L., Cai, X., Yin, Y., Wang, K., Guo, J., Zhang, Y., Chen, J., Guo, X., Li, Q., Li, X., Wang, W., Wang, J., Jiang, X., Xiang, Y., Xu, C., Zheng, P., Zhang, J., Li, R., Zhang, H., Shang, X., Gong, T., Ning, G., Zen, K., and Zhang, C. Y. (2008). Characterization of microRNAs in serum: a novel class of biomarkers for diagnosis of cancer and other diseases. Cell Res. 18, 997-1006.

Chen, X., Hu, Z., Wang, W., Ba, Y., Ma, L., Zhang, C., Wang, C., Ren, Z., Zhao, Y., Wu, S., Zhuang, R., Zhang, Y., Hu, H., Liu, C., Xu, L., Wang, J., Shen, H., Zhang, J., Zen, K., and Zhang, C. Y. (2011). Identification of ten serum microRNAs from a genome-wide serum microRNA expression profile as novel noninvasive biomarkers for nonsmall cell lung cancer diagnosis. Int. J. Cancer. doi: 10.1002/ijc.26177. [Epub ahead of print].

Chen, Z., Zeng, H., Guo, Y., Liu, P., Pan, H., Deng, A., and Hu, J. (2010). miRNA-145 inhibits non-small cell lung cancer cell proliferation by

overwhelming majority of studies is still in the field of basic science and numerous hurdles need to be overcome before any of the miRNA-based approaches can be introduced in clinical practice. As for cancer detection, the major challenge will be the implementation of standardized protocols for the isolation and the analysis of miRNAs. For cancer therapy, robust and specific delivery systems have to be developed for the transport of miRNAs to the tumor site. Finally, both cancer detection and cancer therapy will greatly benefit from a better understanding of the biological role of miRNAs in cancer cells.

\section{ACKNOWLEDGMENTS}

Funding was obtained from Hedwig Stalter foundation, Homburger Forschungsförderungsprogramm (HOMFOR), and Deutsche Forschungsgemeinschaft (DFG).

targeting c-Myc. J. Exp. Clin. Cancer Res. 29, 151.

Ciafre, S. A., Galardi, S., Mangiola, A., Ferracin, M., Liu, C. G., Sabatino, G., Negrini, M., Maira, G., Croce, C. M., and Farace, M. G. (2005). Extensive modulation of a set of microRNAs in primary glioblastoma. Biochem. Biophys. Res. Commun. 334, 1351-1358.

da Cunha Santos, G., Shepherd, F. A. and Tsao, M. S. (2011). EGFR mutations and lung cancer. Annu. Rev. Pathol. 6, 49-69.

Du, L., Schageman, J. J., Subauste, M. C., Saber, B., Hammond, S. M., Prudkin, L., Wistuba, I. I., Ji, L., Roth, J. A., Minna, J. D., and Pertsemlidis, A. (2009). miR-93, miR-98, and miR197 regulate expression of tumor suppressor gene FUS1. Mol. Cancer Res. 7, 1234-1243.

Du, L., Schageman, J. J., Irnov Girard, L., Hammond, S. M., Minna, J. D., Gazdar, A. F., and Pertsemlidis, A. (2010). MicroRNA expression distinguishes SCLC from NSCLC lung tumor cells and suggests a possible pathological relationship between SCLCs and NSCLCs. J. Exp. Clin. Cancer Res. 29, 75.

Esquela-Kerscher, A., Trang, P., Wiggins, J. F., Patrawala, L., Cheng, A., Ford, L., Weidhaas, J. B., Brown, D., Bader, A. G., and Slack, F. J. (2008). The let7 microRNA reduces tumor growth in mouse models of lung cancer. Cell Cycle 7, 759-764.

Feng, S., Cong, S., Zhang, X., Bao, X., Wang, W., Li, H., Wang, Z., Wang, G., Xu, J., Du, B., Qu, D., Xiong, W., Yin, M., Ren, X., Wang, F., He, J., and Zhang, B. (2011). MicroRNA-192 targeting retinoblastoma 1 inhibits cell proliferation and induces cell apoptosis in lung cancer cells. Nucleic Acids Res. 39, 6669-6678.

Foss, K. M., Sima, C., Ugolini, D., Neri, M., Allen, K. E., and Weiss, G. J. (2011). miR-1254 and miR-574-5p: serum-based microRNA biomarkers for early-stage non-small cell lung cancer. J. Thorac. Oncol. 6, 482-488.

Frezzetti, D., De Menna, M., Zoppoli, P., Guerra, C., Ferraro, A., Bello, A. M. De Luca, P., Calabrese, C., Fusco, A., Ceccarelli, M., Zollo, M., Barbacid, M., Di Lauro, R., and De Vita, G. (2011). Upregulation of miR-21 by Ras in vivo and its role in tumor growth. Oncogene 30, 275-286.

Gao, W., Yu, Y., Cao, H., Shen, H., Li, X., Pan, S., and Shu, Y. (2010). Deregulated expression of miR-21, miR-143 and miR-181a in non small cell lung cancer is related to clinicopathologic characteristics or patient prognosis. Biomed. Pharmacother. 64, 399-408.

Guo, H., Ingolia, N. T., Weissman, J. S., and Bartel, D. P. (2010). Mammalian microRNAs predominantly act to decrease target mRNA levels. Nature 466, 835-840.

Hanke, M., Hoefig, K., Merz, H., Feller, A. C., Kausch, I., Jocham, D., Warnecke, J. M., and Sczakiel, G. (2010). A robust methodology to study urine microRNA as tumor marker: microRNA-126 and microRNA-182 are related to urinary bladder cancer. Urol. Oncol. 28, 655-661.

Hayashita, Y., Osada, H., Tatematsu, Y., Yamada, H., Yanagisawa, K., Tomida, S., Yatabe, Y., Kawahara, K., Sekido, Y., and Takahashi, T. (2005). A polycistronic microRNA cluster, miR-17-92, is overexpressed in human lung cancers and enhances cell proliferation. Cancer Res. 65, 9628-9632.

He, L., Thomson, J. M., Hemann, M. T., Hernando-Monge, E., Mu, D., Goodson, S., Powers, S., CordonCardo, C., Lowe, S. W., Hannon, G. J., and Hammond, S. M. (2005). A microRNA polycistron as a potential human oncogene. Nature 435, 828-833. 
Helene, C., and Toulme, J. J. (1990). Specific regulation of gene expression by antisense, sense and antigene nucleic acids. Biochim. Biophys. Acta 1049, 99-125.

Hu, Z., Chen, X., Zhao, Y., Tian, T., Jin, G., Shu, Y., Chen, Y., Xu, L., Zen, K., Zhang, C., and Shen, H. (2010). Serum microRNA signatures identified in a genome-wide serum microRNA expression profiling predict survival of non-small-cell lung cancer. J. Clin. Oncol. 28, 1721-1726.

Hunter, M. P., Ismail, N., Zhang, X., Aguda, B. D., Lee, E. J., Yu, L., Xiao, T., Schafer, J., Lee, M. L., Schmittgen, T. D., Nana-Sinkam, S. P., Jarjoura, D., and Marsh, C. B. (2008). Detection of microRNA expression in human peripheral blood microvesicles. PLoS ONE 3, e3694. doi:10.1371/journal.pone.0003694

Iorio, M. V., Visone, R., Di Leva, G., Donati, V., Petrocca, F., Casalini, P., Taccioli, C., Volinia, S., Liu, C. G., Alder, H., Calin, G. A., Menard, S., and Croce, C. M. (2007). MicroRNA signatures in human ovarian cancer. Cancer Res. 67, 8699-8707.

Jemal, A., Siegel, R., Ward, E., Hao, Y., $\mathrm{Xu}$, J., and Thun, M. J. (2009). Cancer statistics, 2009. CA Cancer J. Clin. $59,225-249$.

Jeong, H. C., Kim, E. K., Lee, J. H., Lee, J. M., Yoo, H. N., and Kim, J. K. (2011). Aberrant expression of let7a miRNA in the blood of non-small cell lung cancer patients. Mol. Med. Report 4, 383-387.

Johnson, C. D., Esquela-Kerscher, A., Stefani, G., Byrom, M., Kelnar, K., Ovcharenko, D., Wilson, M., Wang, X., Shelton, J., Shingara, J., Chin, L., Brown, D., and Slack, F. J. (2007). The let-7 microRNA represses cell proliferation pathways in human cells. Cancer Res. 67, 7713-7722.

Johnson, S. M., Grosshans, H., Shingara, J., Byrom, M., Jarvis, R., Cheng, A., Labourier, E., Reinert, K. L., Brown, D., and Slack, F. J. (2005). RAS is regulated by the let- 7 microRNA family. Cell 120, 635-647.

Kanzaki, H., Ito, S., Hanafusa, H., Jitsumori, Y., Tamaru, S., Shimizu, K., and Ouchida, M. (2011). Identification of direct targets for the miR17-92 cluster by proteomic analysis. Proteomics 11,3531-3539.

Karlsson, H., Bachmann, S., Schroder, J., McArthur, J., Torrey, E. F., and Yolken, R. H. (2001). Retroviral RNA identified in the cerebrospinal fluids and brains of individuals with schizophrenia. Proc. Natl. Acad. Sci. U.S.A. 98, 4634-4639.

Kasinski, A. L., and Slack, F. J. (2011). MicroRNAs en route to the clinic: progress in validating and targeting microRNAs for cancer therapy. Nat. Rev. Cancer 11, 849-864.

Keller, A., Leidinger, P., Bauer, A., ElSharawy, A., Haas, J., Backes, C., Wendschlag, A., Giese, N., Tjaden, C., Ott, K., Werner, J., Hackert, T., Ruprecht, K., Huwer, H., Huebers, J., Jacobs, G., Rosenstiel, P., Dommisch, H., Schaefer, A., MüllerQuernheim, J., Wullich, B., Keck, B., Graf, N., Reichrath, J., Vogel, B., Nebel, A. J., SU Staehler, P., Amarantos, I., Boisguerin, V., Staehler, C., Beier, M., Scheffler, M., Büchler, M., Wischhusen, J., Haeusler, S., Dietl, J., Hofmann, S., Lenhof, H.-P., Schreiber, S., Katus, H., Rottbauer, W., Meder, B., Hoheisel, J., Franke, A., and Meese, E. (2011a). Toward the blood-borne miRNome of human diseases. Nat. Methods 8, 841-843.

Keller, A., Leidinger, P., Gislefoss, R., Haugen, A., Langseth, H., Staehler, P., Lenhof, H. P., and Meese, E. (2011b). Stable serum miRNA profiles as potential tool for noninvasive lung cancer diagnosis. RNA Biol 8, 506-516.

Keller, A., Leidinger, P., Borries, A., Wendschlag, A., Wucherpfennig, F., Scheffler, M., Huwer, H., Lenhof, H. P., and Meese, E. (2009). miRNAs in lung cancer - studying complex fingerprints in patient's blood cells by microarray experiments. BMC Cancer 9, 353. doi:10.1186/1471-2407-9-353

Kosaka, N., Iguchi, H., and Ochiya, T. (2010). Circulating microRNA in body fluid: a new potential biomarker for cancer diagnosis and prognosis. Cancer Sci. 101, 2087-2092.

Kossenkov, A. V., Vachani, A., Chang, C., Nichols, C., Billouin, S., Horng, W., Rom, W. N., Albelda, S. M., Showe, M. K., and Showe, L. C. (2011). Resection of non-small cell lung cancers reverses tumor-induced gene expression changes in the peripheral immune system. Clin. Cancer Res. 17, 5867-5877.

Krutzfeldt, J., Rajewsky, N., Braich, R., Rajeev, K. G., Tuschl, T., Manoharan, M., and Stoffel, M. (2005). Silencing of microRNAs in vivo with "antagomirs." Nature 438, 685-689.

Lai, C. Y., Yu, S. L., Hsieh, M. H., Chen, C. H., Chen, H. Y., Wen, C. C., Huang, Y. H., Hsiao, P. C., Hsiao, C. K., Liu, C. M., Yang, P. C., Hwu, H. G., and Chen, W. J. (2011). MicroRNA expression aberration as potential peripheral blood biomarkers for schizophrenia. PLoS
ONE 6, e21635. doi:10.1371/journal.pone. 0021635

Landen, C. N. Jr., Chavez-Reyes, A., Bucana, C., Schmandt, R., Deavers, M. T., Lopez-Berestein, G., and Sood, A. K. (2005). Therapeutic EphA2 gene targeting in vivo using neutral liposomal small interfering RNA delivery. Cancer Res. 65, 6910-6918.

Landi, M. T., Zhao, Y., Rotunno, M., Koshiol, J., Liu, H., Bergen, A. W., Rubagotti, M., Goldstein, A. M., Linnoila, I., Marincola, F. M., Tucker, M. A., Bertazzi, P. A., Pesatori, A. C. Caporaso, N.E., McShane, L. M., and Wang, E. (2010). MicroRNA expression differentiates histology and predicts survival of lung cancer. Clin. Cancer Res. 16, 430-441.

Lebanony, D., Benjamin, H., Gilad, S. Ezagouri, M., Dov, A., Ashkenazi, K. Gefen, N., Izraeli, S., Rechavi, G. Pass, H., Nonaka, D., Li, J., Spector, Y., Rosenfeld, N., Chajut, A. Cohen, D., Aharonov, R., and Mansukhani, M. (2009). Diagnostic assay based on hsa-miR-205 expression distinguishes squamous from nonsquamous non-small-cell lung carcinoma. J. Clin. Oncol. 27, 2030-2037.

Lee, R. C., Feinbaum, R. L., and Ambros, V. (1993). The C. elegans heterochronic gene lin-4 encodes small RNAs with antisense complementarity to lin-14. Cell 75 843-854.

Leidinger, P., Keller, A., Borries, A., Huwer, H., Rohling, M., Huebers, J., Lenhof, H. P., and Meese, E. (2011). Specific peripheral miRNA profiles for distinguishing lung cancer from COPD. Lung Cancer 74, 41-47.

Liang, Y., Ridzon, D., Wong, L., and Chen, C. (2007). Characterization of microRNA expression profiles in normal human tissues. BMC Genomics 8, 166. doi:10.1186/1471-2164-8-166

Liu, A., and Xu, X. (2011). MicroRNA isolation from formalin-fixed, paraffin-embedded tissues. Methods Mol. Biol. 724, 259-267.

Liu, X. G., Zhu, W. Y., Huang, Y. Y., Ma, L. N., Zhou, S. Q., Wang, Y. K., Zeng, F., Zhou, J. H., and Zhang, Y. K. (2011). High expression of serum miR-2 1 and tumor miR-200c associated with poor prognosis in patients with lung cancer. Med. Oncol. PMID: 21516486. [Epub ahead of print].

Lu, J., Getz, G., Miska, E. A., AlvarezSaavedra, E., Lamb, J., Peck, D. Sweet-Cordero, A., Ebert, B. L., Mak, R. H., Ferrando, A. A. Downing, J. R., Jacks, T., Horvitz, H. R., and Golub, T. R. (2005) MicroRNA expression profiles classify human cancers. Nature 435, 834-838.
Lu, Z., Liu, M., Stribinskis, V., Klinge, C. M., Ramos, K. S., Colburn, N. H., and Li, Y. (2008). MicroRNA-21 promotes cell transformation by targeting the programmed cell death 4 gene. Oncogene 27, 4373-4379.

Markou, A., Tsaroucha, E. G., Kaklamanis, L., Fotinou, M., Georgoulias, V., and Lianidou, E. S. (2008). Prognostic value of mature microRNA-21 and microRNA-205 overexpression in non-small cell lung cancer by quantitative realtime RT-PCR. Clin. Chem. 54, 1696-1704.

Mascaux, C., Laes, J. F., Anthoine, G., Haller, A., Ninane, V., Burny, A., and Sculier, J. P. (2009). Evolution of microRNA expression during human bronchial squamous carcinogenesis. Eur. Respir. J. 33, 352-359.

Matsubara, H., Takeuchi, T., Nishikawa, E., Yanagisawa, K., Hayashita, Y., Ebi, H., Yamada, H., Suzuki, M., Nagino, M., Nimura, Y., Osada, H., and Takahashi, T. (2007). Apoptosis induction by antisense oligonucleotides against miR-17-5p and miR-20a in lung cancers overexpressing miR-1792. Oncogene 26, 6099-6105.

McDermott, A. M., Heneghan, H. M., Miller, N., and Kerin, M. J. (2011). The therapeutic potential of MicroRNAs: disease modulators and drug targets. Pharm. Res. 28, 3016-3029.

Meder, B., Keller, A., Vogel, B., Haas, J., Sedaghat-Hamedani, F., Kayvanpour, E., Just, S., Borries, A., Rudloff, J., Leidinger, P., Meese, E., Katus, H. A., and Rottbauer, W. (2011). MicroRNA signatures in total peripheral blood as novel biomarkers for acute myocardial infarction. Basic Res. Cardiol. 106, 13-23.

Megiorni, F., Pizzuti, A., and Frati, L. (2011). Clinical Significance of MicroRNA Expression profiles and polymorphisms in lung cancer development and management. Patholog. Res. Int. 2011, 780652.

Mehes, G., Witt, A., Kubista, E., and Ambros, P. F. (2001). Circulating breast cancer cells are frequently apoptotic. Am. J. Pathol. 159, 17-20.

Mendell, J. T. (2008). miRiad roles for the miR-17-92 cluster in development and disease. Cell 133, 217-222.

Meng, F., Henson, R., Wehbe-Janek, H., Ghoshal, K., Jacob, S. T., and Patel, T. (2007). MicroRNA-21 regulates expression of the PTEN tumor suppressor gene in human hepatocellular cancer. Gastroenterology 133, 647-658.

Mitchell, P. S., Parkin, R. K., Kroh, E. M., Fritz, B. R., Wyman, S. K., 
Pogosova-Agadjanyan, E. L., Peterson, A., Noteboom, J., O'Briant, K. C., Allen, A., Lin, D. W., Urban, N., Drescher, C. W., Knudsen, B. S., Stirewalt, D. L., Gentleman, R., Vessella, R. L., Nelson, P. S., Martin, D. B., and Tewari, M. (2008). Circulating microRNAs as stable bloodbased markers for cancer detection. Proc. Natl. Acad. Sci. U.S.A. 105, 10513-10518.

Nam, E. J., Yoon, H., Kim, S. W., Kim, H., Kim, Y. T., Kim, J. H., Kim, J. W., and Kim, S. (2008). MicroRNA expression profiles in serous ovarian carcinoma. Clin. Cancer Res. 14, 2690-2695.

Nasser, S., Ranade, A. R., Sridhar, S., Haney, L., Korn, R. L., Gotway, M. B., and Weiss, G. J. (2011). Biomarkers associated with metastasis of lung cancer to brain predict patient survival. Int. J. Data Min. Bioinform. 5, 287-307.

Otaegui, D., Baranzini, S. E., Armananzas, R., Calvo, B., Munoz-Culla, M., Khankhanian, P., Inza, I., Lozano, J. A., Castillo-Trivino, T., Asensio, A., Olaskoaga, J., and Lopez de Munain, A. (2009). Differential micro RNA expression in PBMC from multiple sclerosis patients. PLoS ONE 4, e6309. doi:10.1371/journal.pone.0006309

Pardoll, D. (2003). Does the immune system see tumors as foreign or self? Annu. Rev. Immunol. 21, 807-839.

Park, N. J., Li, Y., Yu, T., Brinkman, B. M., and Wong, D. T. (2006). Characterization of RNA in saliva. Clin. Chem. 52, 988-994.

Park, N. J., Zhou, H., Elashoff, D., Henson, B. S., Kastratovic, D. A., Abemayor, E., and Wong, D. T. (2009). Salivary microRNA: discovery, characterization, and clinical utility for oral cancer detection. Clin. Cancer Res. 15, 5473-5477.

Porkka, K. P., Pfeiffer, M. J., Waltering, K. K., Vessella, R. L., Tammela, T. L., and Visakorpi, T. (2007). MicroRNA expression profiling in prostate cancer. Cancer Res. 67, 6130-6135.

Pottelberge, G. R., Mestdagh, P., Bracke, K. R., Thas, O., Durme, Y. M., Joos, G. F., Vandesompele, J., and Brusselle, G. G. (2011). MicroRNA expression in induced sputum of smokers and patients with chronic obstructive pulmonary disease. Am. J. Respir. Crit. Care Med. 183, 898-906.

Rabinowits, G., Gercel-Taylor, C., Day, J. M., Taylor, D. D., and Kloecker, G. H. (2009). Exosomal microRNA: a diagnostic marker for lung cancer. Clin. Lung Cancer 10, 42-46.

Raponi, M., Dossey, L., Jatkoe, T., Wu, X., Chen, G., Fan, H., and Beer, D. G. (2009). MicroRNA classifiers for predicting prognosis of squamous cell lung cancer. Cancer Res. 69, 5776-5783.

Reiber, H., and Peter, J. B. (2001). Cerebrospinal fluid analysis: disease-related data patterns and evaluation programs. J. Neurol. Sci. 184, 101-122.

Schipper, H. M., Maes, O. C., Chertkow, H. M., and Wang, E. (2007). MicroRNA expression in Alzheimer blood mononuclear cells. Gene Regul. Syst. Bio. 1, 263-274.

Schmidt, B., Engel, E., Carstensen, T., Weickmann, S., John, M., Witt, C., and Fleischhacker, M. (2005). Quantification of free RNA in serum and bronchial lavage: a new diagnostic tool in lung cancer detection? Lung Cancer 48, 145-147.

Seike, M., Goto, A., Okano, T., Bowman, E. D., Schetter, A. J., Horikawa, I., Mathe, E. A., Jen, J., Yang, P., Sugimura, H., Gemma, A., Kudoh, S., Croce, C. M., and Harris, C. C. (2009). MiR-21 is an EGFR-regulated anti-apoptotic factor in lung cancer in never-smokers. Proc. Natl. Acad. Sci. U.S.A. 106, 12085-12090.

Sethupathy, P., Megraw, M., and Hatzigeorgiou, A. G. (2006). A guide through present computational approaches for the identification of mammalian microRNA targets. Nat. Methods 3, 881-886.

Shahzad, M. M., Mangala, L. S., Han, H. D., Lu, C., Bottsford-Miller, J., Nishimura, M., Mora, E. M., Lee, J. W., Stone, R. L., Pecot, C. V., Thanapprapasr, D., Roh, J. W., Gaur, P., Nair, M. P., Park, Y. Y., Sabnis, N., Deavers, M. T., Lee, J. S., Ellis, L. M., Lopez-Berestein, G., McConathy, W. J., Prokai, L., Lacko, A. G., and Sood, A. K. (2011). Targeted delivery of small interfering RNA using reconstituted high-density lipoprotein nanoparticles. Neoplasia 13, 309-319.

Shen, J., Todd, N. W., Zhang, H., Yu, L., Lingxiao, X., Mei, Y., Guarnera, M., Liao, J., Chou, A., Lu, C. L., Jiang, Z., Fang, H., Katz, R. L., and Jiang, F. (2011). Plasma microRNAs as potential biomarkers for nonsmall-cell lung cancer. Lab. Invest. 91, 579-587.

Shi, S. J., Zhong, Z. R., Liu, J., Zhang, Z. R., Sun, X., and Gong, T. (2011). Solid lipid nanoparticles loaded with anti-microRNA oligonucleotides (AMOs) for suppression of microRNA-21 functions in human lung cancer cells. Pharm. Res. 29, 97-109.

Takamizawa, J., Konishi, H., Yanagisawa, K., Tomida, S., Osada, H., Endoh, H., Harano, T., Yatabe, Y., Nagino, M., Nimura, Y., Mitsudomi, T., and Takahashi, T. (2004). Reduced expression of the let-7 microRNAs in human lung cancers in association with shortened postoperative survival. Cancer Res. 64, 3753-3756.

Thunnissen, F. B. (2003). Sputum examination for early detection of lung cancer. J. Clin. Pathol. 56, 805-810.

Tomankova, T., Petrek, M., and Kriegova, E. (2010). Involvement of microRNAs in physiological and pathological processes in the lung. Respir. Res. 11, 159.

Trang, P., Medina, P. P., Wiggins, J. F., Ruffino, L., Kelnar, K., Omotola, M., Homer, R., Brown, D., Bader, A. G., Weidhaas, J. B., and Slack, F. J. (2010). Regression of murine lung tumors by the let-7 microRNA. Oncogene 29, 1580-1587.

Trang, P., Wiggins, J. F., Daige, C. L., Cho, C., Omotola, M., Brown, D., Weidhaas, J. B., Bader, A. G., and Slack, F J. (2011). Systemic delivery of tumor suppressor microRNA mimics using a neutral lipid emulsion inhibits lung tumors in mice. Mol. Ther. 19, 1116-1122.

Tzimagiorgis, G., Michailidou, E. Z., Kritis, A., Markopoulos, A. K., and Kouidou, S. (2011). Recovering circulating extracellular or cell-free RNA from bodily fluids. Cancer Epidemiol. 35, 580-589.

van Kouwenhove, M., Kedde, M., and Agami, R. (2011). MicroRNA regulation by RNA-binding proteins and its implications for cancer. Nat. Rev. Cancer 11, 644-656.

Vasudevan, S., Tong, Y., and Steitz, J. A. (2007). Switching from repression to activation: microRNAs can up-regulate translation. Science 318 , 1931-1934.

Voellenkle, C., van Rooij, J., Cappuzzello, C., Greco, S., Arcelli, D., Di Vito, L., Melillo, G., Rigolini, R., Costa, E., Crea, F., Capogrossi, M. C., Napolitano, M., and Martelli, F. (2010). MicroRNA signatures in peripheral blood mononuclear cells of chronic heart failure patients. Physiol. Genomics 42, 420-426.

Volinia, S., Calin, G. A., Liu, C. G., Ambs, S., Cimmino, A., Petrocca, F.,
Visone, R., Iorio, M., Roldo, C., Ferracin, M., Prueitt, R. L., Yanaihara, N., Lanza, G., Scarpa, A., Vecchione, A., Negrini, M., Harris, C. C., and Croce, C. M. (2006). A microRNA expression signature of human solid tumors defines cancer gene targets. Proc. Natl. Acad. Sci. U.S.A. 103, 2257-2261.

Vosa, U., Vooder, T., Kolde, R., Fischer, K., Valk, K., Tonisson, N., Roosipuu, R., Vilo, J., Metspalu, A., and Annilo, T. (2011). Identification of miR-374a as a prognostic marker for survival in patients with early-stage nonsmall cell lung cancer. Genes Chromosomes Cancer 50, 812-822.

Wang, G., Tam, L. S., Li, E. K., Kwan, B. C., Chow, K. M., Luk, C. C., Li, P. K., and Szeto, C. C. (2011). Serum and urinary free microRNA level in patients with systemic lupus erythematosus. Lupus 20, 493-500.

Weber, J. A., Baxter, D. H., Zhang, S., Huang, D. Y., Huang, K. H., Lee, M. J., Galas, D. J., and Wang, K. (2010). The microRNA spectrum in 12 body fluids. Clin. Chem. 56, 1733-1741.

Weiss, G. J., Bemis, L. T., Nakajima, E., Sugita, M., Birks, D. K., Robinson, W. A., Varella-Garcia, M., Bunn, P. A. Jr., Haney, J., Helfrich, B. A., Kato, H., Hirsch, F. R., and Franklin, W. A. (2008). EGFR regulation by microRNA in lung cancer: correlation with clinical response and survival to gefitinib and EGFR expression in cell lines. Ann. Oncol. 19, 1053-1059.

Wiggins, J. F., Ruffino, L., Kelnar, K., Omotola, M., Patrawala, L., Brown, D., and Bader, A. G. (2010). Development of a lung cancer therapeutic based on the tumor suppressor microRNA-34. Cancer Res. 70, 5923-5930.

Wu, Y., Crawford, M., Yu, B., Mao, Y., Nana-Sinkam, S. P., and Lee, L. J. (2011). MicroRNA delivery by cationic lipoplexes for lung cancer therapy. Mol. Pharm. 8, 1381-1389.

Xie, Y., Todd, N. W., Liu, Z., Zhan, M., Fang, H., Peng, H., Alattar, M., Deepak, J., Stass, S. A., and Jiang, F. (2010). Altered miRNA expression in sputum for diagnosis of nonsmall cell lung cancer. Lung Cancer 67, 170-176.

Xing, L., Todd, N. W., Yu, L., Fang, H., and Jiang, F. (2010). Early detection of squamous cell lung cancer in sputum by a panel of microRNA markers. Mod. Pathol. 23 , 1157-1164. 
Xiong, S., Zheng, Y., Jiang, P., Liu, R., Liu, X., and Chu, Y. (2011). MicroRNA7 inhibits the growth of human non-small cell lung cancer A549 cells through targeting BCL-2. Int. J. Biol. Sci. 7, 805-814.

Yanaihara, N., Caplen, N., Bowman, E., Seike, M., Kumamoto, K., Yi, M., Stephens, R. M., Okamoto, A., Yokota, J., Tanaka, T., Calin, G. A., Liu, C. G., Croce, C. M., and Harris, C. C. (2006). Unique microRNA molecular profiles in lung cancer diagnosis and prognosis. Cancer Cell 9, 189-198.
Yu, L., Todd, N. W., Xing, L., Xie, Y., Zhang, H., Liu, Z., Fang, H., Zhang, J., Katz, R. L., and Jiang, F. (2010). Early detection of lung adenocarcinoma in sputum by a panel of microRNA markers. Int. J. Cancer 127, 2870-2878.

Zhang, J. G., Wang, J. J., Zhao, F., Liu, Q., Jiang, K., and Yang, G. H. (2010). MicroRNA-21 (miR-21) represses tumor suppressor PTEN and promotes growth and invasion in non-small cell lung cancer (NSCLC). Clin. Chim. Acta 411, 846-852.
Zhang, Y. A., Nemunaitis, J., Samuel, S. K., Chen, P., Shen, Y., and Tong, A. W. (2006). Antitumor activity of an oncolytic adenovirusdelivered oncogene small interfering RNA. Cancer Res. 66, 9736-9743.

Conflict of Interest Statement: Siemens Healthcare employs Andreas Keller.

Received: 14 October 2011; paperpending published: 18 November 2011; accepted: 20 December 2011; published online: 23 January 2012.
Citation: Leidinger P, Keller A and Meese E (2012) MicroRNAs - important molecules in lung cancer research. Front. Gene. 2:104. doi: 10.3389/fgene.2011.00104

This article was submitted to Frontiers in Cancer Genetics, a specialty of Frontiers in Genetics.

Copyright (C) 2012 Leidinger, Keller and Meese. This is an open-access article distributed under the terms of the Creative Commons Attribution Non Commercial License, which permits noncommercial use, distribution, and reproduction in other forums, provided the original authors and source are credited. 


\section{APPENDIX}

Table A1 | Summary of miRNAs associated with lung cancer.

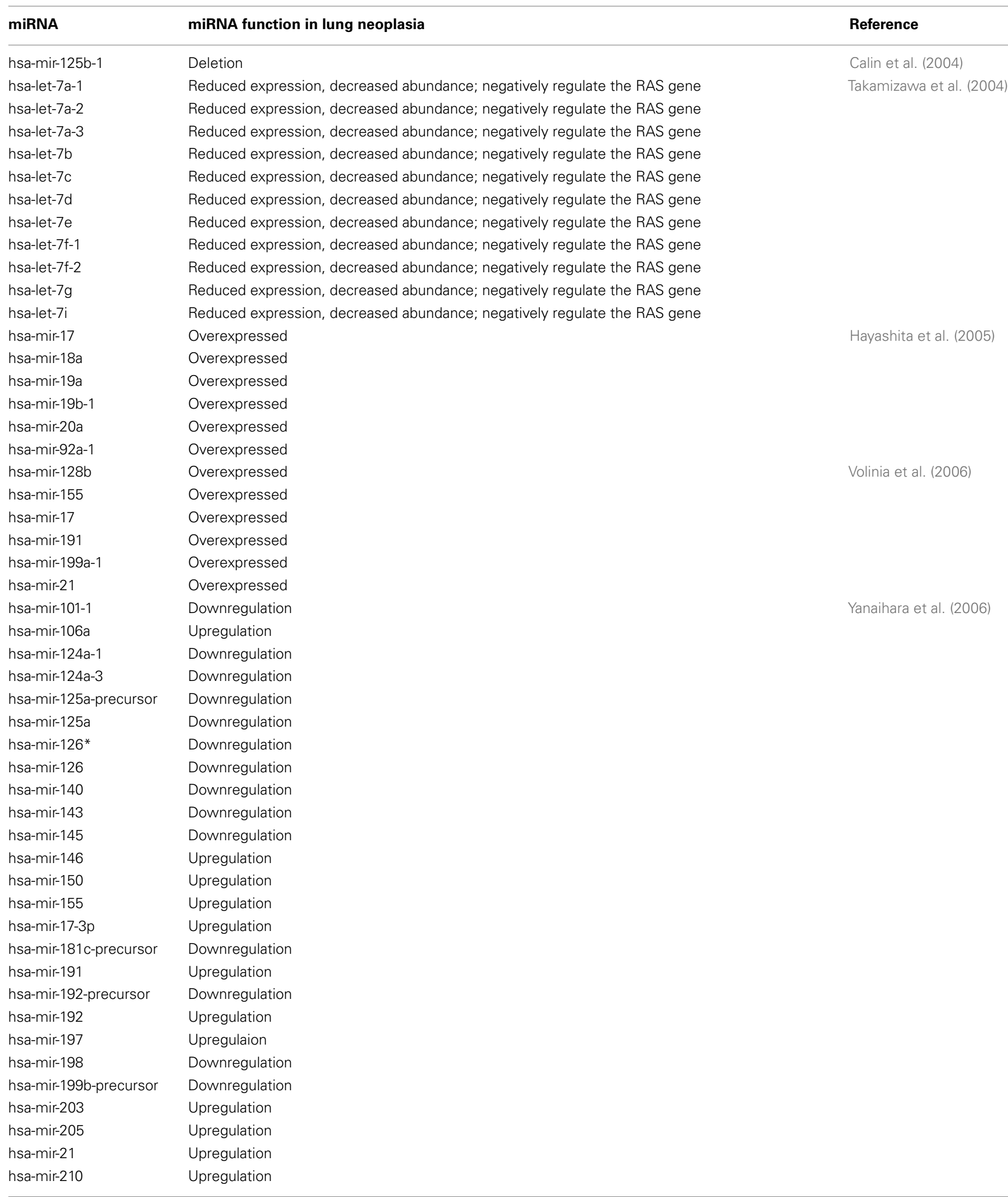


Table A1 | Continued

\section{miRNA}

hsa-mir-212
hsa-mir-214
hsa-mir-216-precursor
hsa-mir-218-2
hsa-mir-219-1
hsa-mir-220
hsa-mir-224
hsa-mir-24-2
hsa-mir-26a-1-precursor
hsa-mir-27b
hsa-mir-29b-2
hsa-mir-30a-5p
hsa-mir-32
hsa-mir-33
hsa-mir-9
hsa-mir-95
hsa-let-7a-2-precursor
hsa-mir-132

hsa-mir-29a

hsa-mir-29b-1

hsa-mir-29c

hsa-mir-128b

hsa-mir-126

hsa-mir-1

hsa-mir-183

hsa-let-7a

hsa-let-7b

hsa-let-7d

hsa-let-7g

hsa-mir-126

hsa-mir-142-5p

hsa-mir-145

hsa-mir-34c

hsa-mir-205

hsa-mir-196a-2

hsa-miR-21

hsa-mir-141

hsa-mir-210

hsa-mir-200b

hsa-mir-346

hsa-mir-126*

hsa-mir-126

hsa-mir-30a

hsa-mir-30d
miRNA function in lung neoplasia

Reference

Upregulation

Upregulation

Downregulation

Downregulation

Downregulation

Downregulation

Downregulation

Upregulation

Downregulation

Downregulation

Downregulation

Downregulation

Downregulation

Downregulation

Downregulation

Downregulation

Downregulation

miR-132, previously shown to be differentially upregulated in six solid cancer types (breast, colon, lung, pancreas, prostate, and stomach carcinomas)

miR-29 family $(29 a, b, c)$ reverts aberrant methylation in lung cancer by targeting DNA

methyltransferases $3 \mathrm{~A}$ and $3 \mathrm{~B}$

miR-29 family $(29 a, b, c)$ reverts aberrant methylation in lung cancer by targeting DNA

methyltransferases $3 \mathrm{~A}$ and $3 \mathrm{~B}$

miR-29 family $(29 a, b, c)$ reverts aberrant methylation in lung cancer by targeting DNA

methyltransferases $3 \mathrm{~A}$ and $3 \mathrm{~B}$

Increased

Inhibits invasion in non-small cell lung carcinoma cell lines

Downregulated

Potential metastasis-inhibitor

let-7a: A SNP in a let-7 microRNA complementary site in the KRAS $3^{\prime}$ untranslated region increases non-small cell lung cancer risk

let-7b: A SNP in a let-7 microRNA complementary site in the KRAS $3^{\prime}$ untranslated region increases non-small cell lung cancer risk

let-7d: A SNP in a let-7 microRNA complementary site in the KRAS $3^{\prime}$ untranslated region increases non-small cell lung cancer risk

let-7g: A SNP in a let-7 microRNA complementary site in the KRAS $3^{\prime}$ untranslated region increases non-small cell lung cancer risk

Inhibits the growth of lung cancer cell line

Was repressed, overexpression can inhibit lung cancer growth

Liu et al. (2009a)

Liu et al. (2009b)

Was repressed, overexpression can inhibit lung cancer growth

Was repressed, overexpression can inhibit lung cancer growth

Highly specific marker for squamous cell lung carcinoma

Genetic variant is associated with increased susceptibility of lung cancer in Chinese

Upregulated in lung cancer in never-smokers

Upregulated in lung cancer in never-smokers

Upregulated in lung cancer in never-smokers

Upregulated in lung cancer in never-smokers

Upregulated in lung cancer in never-smokers

Downregulated in lung cancer in never-smokers

Downregulated in lung cancer in never-smokers

Downregulated in lung cancer in never-smokers

Downregulated in lung cancer in never-smokers
Lee et al. (2007)

Fabbri et al. (2007)

Weiss et al. (2008)

Crawford et al. (2008)

Nasser et al. (2008)

Wang et al. (2008)

Chin et al. (2008)
Lebanony et al. (2009)

Tian et al. (2009)

Seike et al. (2009) 


\section{Table A1 | Continued}

\section{miRNA}

miRNA function in lung neoplasia

Reference

hsa-mir-486

hsa-mir-129

hsa-mir-451

hsa-mir-521

hsa-mir-138

hsa-mir-30b

hsa-mir-30c

hsa-mir-516a

hsa-mir-520

hsa-mir-17-5p

hsa-mir-20a

hsa-mir-145

hsa-mir-142-5p

hsa-mir-34c

hsa-mir-133b

hsa-mir-98

hsa-mir-197

hsa-mir-93

hsa-mir-185

hsa-miR-107

hsa-mir-34a

hsa-let-7g

hsa-mir-34a

hsa-mir-133b

hsa-mir-486-5p

hsa-mir-629

hsa-let-7a

hsa-mir-126

hsa-mir-145

hsa-mir-181b

hsa-mir-486

hsa-mir-30d

hsa-mir-499

hsa-mir-1

hsa-mir-21

hsa-mir-136

Downregulated in lung cancer in never-smokers

Downregulated in lung cancer in never-smokers

Downregulated in lung cancer in never-smokers

Downregulated in lung cancer in never-smokers

Downregulated in lung cancer in never-smokers

Downregulated in lung cancer in never-smokers

Downregulated in lung cancer in never-smokers

Downregulated in lung cancer in never-smokers

Downregulated in lung cancer in never-smokers

miR-17-92 cluster may contribute to protect SCLC cells carrying RB inactivation from excessive

Ebi et al. (2009)

DNA damage and paradoxical growth inhibitory effects, to a large extent by direct

downregulation of E2F1 expression. Overexpression involved in fine-tuning ROS generation

miR-17-92 cluster may contribute to protect SCLC cells carrying RB inactivation from excessive

DNA damage and paradoxical growth inhibitory effects, to a large extent by direct

downregulation of E2F1 expression. Overexpression involved in fine-tuning ROS generation

miR-34c, miR-145, or miR-142-5p expression markedly diminished proliferation of lung cancer

cell lines, clinical implications discussed

miR-34c, miR-145, or miR-142-5p expression markedly diminished proliferation of lung cancer

cell lines, clinical implications discussed

miR-34c, miR-145, or miR-142-5p expression markedly diminished proliferation of lung cancer

cell lines, clinical implications discussed

Low expression, targets pro-survival molecules MCL-1 and BCL-2L2

Regulate tumor suppressor gene FUS1

Crawford et al. (2009)

Du et al. (2009)

Regulate tumor suppressor gene FUS1

Regulate tumor suppressor gene FUS1

Cell cycle arrest

Cell cycle arrest

Prognostic marker of relapse in surgically resected non-small cell lung cancer

let-7g was downregulated in radio-resistant $\mathrm{H} 1299$ cells; increased with response to ionizing

radiation when knockdown LIN28B

miR-34a:MicroRNA-34a is an important component of PRIMA-1-induced apoptotic network in

human lung cancer cells

Downregulated

Downregulated

Upregulated

Inhibition of proliferation in non-small cell lung cancer

Sempere et al. (2009)

Du etal. (2009)

Takahashi et al. (2009)

Gallardo et al. (2009)

Jeong et al. (2009)

Duan et al. (2010)

Navon et al. (2009)

Zhong et al. (2010)

Inhibition of proliferation in non-small cell lung cancer

Inhibition of proliferation in non-small cell lung cancer

Modulates multidrug resistance by targeting BCL-2 in human cancer cell lines

Levels of four miRNAs (i.e., miR-486, miR-30d, miR-1, and miR-499) were significantly

Zhu et al. (2010a)

Hu et al. (2010)

associated with overall survival

Levels of four miRNAs (i.e., miR-486, miR-30d, miR-1, and miR-499) were significantly

associated with overall survival

Levels of four miRNAs (i.e., miR-486, miR-30d, miR-1, and miR-499) were significantly

associated with overall survival

Levels of four miRNAs (i.e., miR-486, miR-30d, miR-1, and miR-499) were significantly

associated with overall survival

MicroRNA-21 (miR-21) represses tumor suppressor PTEN and promotes growth and invasion in

Zhang et al. (2010b)

non-small cell lung cancer (NSCLC)

We found that miR-136, miR-376a, and miR-31 were each prominently overexpressed in murine

Liu et al. (2010)

lung cancers

(Continued) 


\section{Table A1 | Continued}

\section{miRNA}

miRNA function in lung neoplasia

Reference

hsa-mir-376a

hsa-mir-31

hsa-mir-182

hsa-mir-148a

hsa-mir-301a

hsa-mir-34a

hsa-mir-103

hsa-mir-107

hsa-mir-301

hsa-mir-338

hsa-mir-186*

hsa-mir-206

hsa-mir-497

hsa-mir-145

hsa-mir-638

hsa-mir-923

hsa-mir-34b

hsa-let-7a-2

hsa-mir-200

hsa-mir-9

hsa-let-7g

hsa-let-7g

hsa-mir-145

hsa-mir-196a-2

hsa-mir-145

hsa-mir-182

hsa-mir-21

hsa-mir-200c

hsa-mir-222

hsa-mir-155
We found that miR-136, miR-376a, and miR-31 were each prominently overexpressed in murine lung cancers

We found that miR-136, miR-376a, and miR-31 were each prominently overexpressed in murine lung cancers

Suppresses lung tumorigenesis through downregulation of RGS17 expression in vitro

The silencing of mir-148a production by DNA hypermethylation is an early event in pancreatic

carcinogenesis

Blocking of miR-301 in A549 cells leads to a decrease in the expression of the host gene, ska2

Development of a lung cancer therapeutic based on the tumor suppressor microRNA-34

Significant overexpression of miR-103, miR-107, miR-301, and miR-338 in lung cancer cells as

compared to HBECs

Significant overexpression of miR-103, miR-107, miR-301, and miR-338 in lung cancer cells as compared to HBECs

Significant overexpression of miR-103, miR-107, miR-301, and miR-338 in lung cancer cells as compared to HBECs

Significant overexpression of miR-103, miR-107, miR-301, and miR-338 in lung cancer cells as compared to HBECs

May serve as a potential gene therapy target for refractory lung cancer that is sensitive to curcumin

Associated with invasion and metastasis of lung cancer

Modulates multidrug resistance of human cancer cell lines by targeting BCL-2

Inhibits cell proliferation of human lung adenocarcinoma by targeting EGFR and NUDT1

Upregulation of mir-638 and mir-923 in bostrycin-treated lung adenocarcinoma cells

Upregulation of mir-638 and mir-923 in bostrycin-treated lung adenocarcinoma cells

Suppresses the expression of $\alpha 4$ through specific binding to the 3 '-untranslated region of $\alpha 4$ is

downregulated in transformed or human lung tumors

9-cis-RA, all-trans-RA, lithium chloride and $\mathrm{CEBP} \alpha$ might play important regulatory roles in let-7a2 gene expression in A549 cells

The notch ligand Jagged2 promotes lung adenocarcinoma metastasis through a

miR-200-dependent pathway in mice

Enhances the sensitivity to ionizing radiation by suppression of NFKB1

Enhances the sensitivity to ionizing radiation by suppression of NFKB1

Precursor let-7g microRNA can supress A549 lung cancer cell migration

Suppresses lung adenocarcinoma-initiating cell proliferation by targeting OCT4

hsa-miR-196a2 rs11614913 polymorphism may contribute to the susceptibility of cancers. CC genotype might modulate lung cancer risk $(\mathrm{OR}=1.25,95 \% \mathrm{Cl}=1.06-1.46$,

pheterogeneity $=0.958$ )

Inhibits lung adenocarcinoma stem cells proliferation by targeting OCT4 gene

Inhibits the proliferation and invasion of human lung adenocarcinoma cells through its effect on

human cortical actin-associated protein

High expression of serum miR-21 associated with poor prognosis in patients with lung cancer

High expression of tumor miR-200c associated with poor prognosis in patients with lung cancer

High-mobility group A1 proteins enhance the expression of the oncogenic miR-222 in lung

cancer cells.

Could significantly inhibit the growth of human lung cancer 95D cells in vitro, which might be

closely related to miR-155 induced G0/G1 phase arrest
Sun et al. (2010)

Hanoun et al. (2010)

Cao et al. (2010)

Wiggins et al. (2010)

Du et al. (2010)

Zhang et al. (2010a)

Wang et al. (2010)

Zhu et al. (2010b)

Cho et al. (2011)

Chen et al. (2011b)

Chen et al. (2011a)

Guan et al. (2011)

Yang et al. (2011)

Arora et al. (2011a)

Park et al. (2011)

Yin et al. (2011)

Chu et al. (2011)

Zhang et al. (2011b)

Zhang et al. (2011a)

Liu et al. (2011)

Zhang et al. (2011c)

Qin et al. (2011) 


\section{Table A1 | Continued}

\section{miRNA}

hsa-mir-125a-5p

hsa-mir-146b

hsa-mir-101

hsa-mir-375

hsa-mir-26b

hsa-mir-155

hsa-mir-197

hsa-mir-182

hsa-mir-183

hsa-mir-96

hsa-mir-150

hsa-mir-200b

hsa-mir-9

hsa-mir-182

hsa-mir-200a +

hsa-mir-151

hsa-mir-205

hsa-mir-183

hsa-mir-130b*

hsa-mir-149

hsa-mir-193b

hsa-mir-339-5p

hsa-mir-196b

hsa-mir-224

hsa-mir-31

hsa-mir-196a

hsa-mir-423-3p

hsa-mir-708

\section{miRNA function in lung neoplasia}

Induces apoptosis by activating p53 in lung cancer cells

Overexpression of the Lung Cancer-prognostic miR-146b has a minimal and negative effect on the malignant phenotype of A549 Lung cancer cells

miR-101 DNA copy loss is a prominent subtype specific event in lung cancer

miR-375 is activated by ASH1 and inhibits YAP1 in a lineage dependent manner in lung cancer

Expression of miR-26b was downregulated, and its target activating transcription factor 2 (ATF2) mRNA was up regulated in $\gamma$-irradiated $\mathrm{H} 1299$ cells

The levels of miR-155, miR-197, and miR-182 in the plasma of lung cancer including stage I patients were significantly elevated compared with controls $(P<0.001)$. The combination of these three miRNAs yielded $81.33 \%$ sensitivity and $86.76 \%$ specificity in discriminating lung cancer patients from controls. The levels of miR-155 and miR-197 were higher in the plasma from lung cancer patients with metastasis than in those without metastasis $(P<0.05)$ and were significantly decreased in responsive patients during chemotherapy $(P<0.001)$

The levels of miR-155, miR-197, and miR-182 in the plasma of lung cancer including stage I patients were significantly elevated compared with controls $(P<0.001)$. The combination of these three miRNAs yielded $81.33 \%$ sensitivity and $86.76 \%$ specificity in discriminating lung cancer patients from controls. The levels of miR-155 and miR-197 were higher in the plasma from lung cancer patients with metastasis than in those without metastasis $(P<0.05)$ and were significantly decreased in responsive patients during chemotherapy $(P<0.001)$

The levels of miR-155, miR-197, and miR-182 in the plasma of lung cancer including stage I patients were significantly elevated compared with controls $(P<0.001)$. The combination of these three miRNAs yielded $81.33 \%$ sensitivity and $86.76 \%$ specificity in discriminating lung cancer patients from controls. The levels of miR-155 and miR-197 were higher in the plasma from lung cancer patients with metastasis than in those without metastasis $(P<0.05)$ and were significantly decreased in responsive patients during chemotherapy $(P<0.001)$

Expression levels of members of the miR-183 family in lung cancer tumor and sera were higher than that of their normal counterparts. The miR-96 expression in tumors was positively associated with its expression in sera. High expression of tumor and serum miRNAs of the miR-183 family were associated with overall poor survival in patients with lung cancer Expression levels of members of the miR-183 family in lung cancer tumor and sera were higher than that of their normal counterparts. The miR-96 expression in tumors was positively associated with its expression in sera. High expression of tumor and serum miRNAs of the miR-183 family were associated with overall poor survival in patients with lung cancer Anti-miR-150 vector can regress A549 lung cancer tumors Stably expressing microRNA-200b in As-p53lowHBECs (human bronchial epithelial cell) abolished Akt and Erk1/2 activation, and completely suppressed cell migration and invasion Upregulated in NSCLC compared to non-tumorous tissue Upregulated in NSCLC compared to non-tumorous tissue Upregulated in NSCLC compared to non-tumorous tissue Upregulated in NSCLC compared to non-tumorous tissue Upregulated in NSCLC compared to non-tumorous tissue Upregulated in NSCLC compared to non-tumorous tissue Upregulated in NSCLC compared to non-tumorous tissue Upregulated in NSCLC compared to non-tumorous tissue Upregulated in NSCLC compared to non-tumorous tissue Upregulated in NSCLC compared to non-tumorous tissue Upregulated in NSCLC compared to non-tumorous tissue Upregulated in NSCLC compared to non-tumorous tissue Upregulated in NSCLC compared to non-tumorous tissue Upregulated in NSCLC compared to non-tumorous tissue Upregulated in NSCLC compared to non-tumorous tissue Upregulated in NSCLC compared to non-tumorous tissue

\section{Reference}

Jiang et al. (2011)

Patnaik et al. (2011)

Thu et al. (2011)

Nishikawa et al. (2011)

Arora et al. (2011b)

Zheng et al. (2011)

Zhu et al. (2011)

Li et al. (2011)

Wang et al. (2011b)

Vosa et al. (2011) 


\section{Table A1 | Continued}

\section{miRNA}

miRNA function in lung neoplasia

Reference

hsa-mir-106b*

hsa-mir-210

hsa-mir-1273

hsa-mir-206

hsa-mir-140-3p

hsa-mir-338-3p

hsa-mir-101

hsa-mir-144

hsa-mir-1285

hsa-mir-130a

hsa-mir-486-5p

hsa-mir-24-2*

hsa-mir-144*

hsa-mir-30a

hsa-mir-20a

hsa-mir-24

hsa-mir-25

hsa-mir-145

hsa-mir-152

hsa-mir-199a-5p

hsa-mir-221

hsa-mir-222

hsa-mir-223

hsa-mir-320

hsa-mir-126

hsa-mir-let-7a

hsa-mir-495

hsa-mir-451

hsa-mir-128b

hsa-mir-130a

hsa-mir-106b

hsa-mir-19b

hsa-mir-22

hsa-mir-15b

hsa-mir-17-5p

hsa-mir-21

hsa-miR-126

hsa-miR-193a-3p

hsa-miR-30d

hsa-miR-30a

Upregulated in NSCLC compared to non-tumorous tissue

Upregulated in NSCLC compared to non-tumorous tissue

Downregulated in NSCLC compared to non-tumorous tissue

Downregulated in NSCLC compared to non-tumorous tissue

Downregulated in NSCLC compared to non-tumorous tissue

Downregulated in NSCLC compared to non-tumorous tissue

Downregulated in NSCLC compared to non-tumorous tissue

Downregulated in NSCLC compared to non-tumorous tissue

Downregulated in NSCLC compared to non-tumorous tissue

Downregulated in NSCLC compared to non-tumorous tissue

Downregulated in NSCLC compared to non-tumorous tissue

Downregulated in NSCLC compared to non-tumorous tissue

Downregulated in NSCLC compared to non-tumorous tissue

Downregulated in NSCLC compared to non-tumorous tissue

Upregulated in NSCLC serum compared to control serum

Chen et al. (2011c)

Upregulated in NSCLC serum compared to control serum

Upregulated in NSCLC serum compared to control serum

Upregulated in NSCLC serum compared to control serum

Upregulated in NSCLC serum compared to control serum

Upregulated in NSCLC serum compared to control serum

Upregulated in NSCLC serum compared to control serum

Upregulated in NSCLC serum compared to control serum

Upregulated in NSCLC serum compared to control serum

Upregulated in NSCLC serum compared to control serum

Upregulated in radiotherapy sensitive patients compared to resistant patients of non-small cell

Wang et al. (2011a) lung cancer

Upregulated in radiotherapy sensitive patients compared to resistant patients of non-small cell lung cancer

Upregulated in radiotherapy sensitive patients compared to resistant patients of non-small cell lung cancer

Upregulated in radiotherapy sensitive patients compared to resistant patients of non-small cell lung cancer

Upregulated in radiotherapy sensitive patients compared to resistant patients of non-small cell lung cancer

Downregulated in radiotherapy sensitive patients compared to resistant patients of non-small cell lung cancer

Downregulated in radiotherapy sensitive patients compared to resistant patients of non-small cell lung cancer

Downregulated in radiotherapy sensitive patients compared to resistant patients of non-small cell lung cancer

Downregulated in radiotherapy sensitive patients compared to resistant patients of non-small cell lung cancer

Downregulated in radiotherapy sensitive patients compared to resistant patients of non-small cell lung cancer

Downregulated in radiotherapy sensitive patients compared to resistant patients of non-small cell lung cancer

Downregulated in radiotherapy sensitive patients compared to resistant patients of non-small cell lung cancer

Downregulated in lung SCC compared to normal lung tissues

Yang et al. (2010)

Downregulated in lung SCC compared to normal lung tissues

Downregulated in lung SCC compared to normal lung tissues

(Continued) 


\section{Table A1 | Continued}

\section{miRNA}

miRNA function in lung neoplasia

Reference

hsa-miR-101

hsa-let-7i

hsa-miR-15a

hsa-miR-185 *

hsa-miR-125a-5p

hsa-let-7f

hsa-miR-20b

hsa-miR-30e-3p

hsa-miR-21

hsa-miR-182

hsa-let-7-5a

hsa-miR-145

hsa-miR-155

hsa-miR-21

hsa-mir-143

hsa-mir-181a

hsa-let-7g

hsa-let-7b

hsa-let-7c

hsa-miR-29a

hsa-let-7f

has-miR-453

hsa-let-7d

hsa-miR-98

hsa-let-7i

hsa-miR-26a

hsa-miR-509-3p

hsa-miR-30b

hsa-miR-146b-5p

hsa-miR-106b

hsa-let-7a

hsa-mir-663

hsa-miR-30d

hsa-miR-17

hsa-miR-498

hsa-miR-26b

hsa-let-7e

hsa-mir-654-5p

hsa-miR-181a

hsa-miR-103

hsa-miR-195

hsa-miR-191

hsa-miR-20a

hsa-miR-106a

hsa-miR-29c
Downregulated in lung SCC compared to normal lung tissues

Downregulated in lung SCC compared to normal lung tissues

Downregulated in lung SCC compared to normal lung tissues

Upregulated in lung SCC compared to normal lung tissues

Upregulated in lung SCC compared to normal lung tissues

Decreased in plasma vesicles from 28 NSCLC patients and 20 controls. Plasma levels of

Silva et al. (2011)

mir-30e-3p and let-7f were associated with short disease-free survival and overall survival

Decreased in plasma vesicles from 28 NSCLC patients and 20 controls

Decreased in plasma vesicles from 28 NSCLC patients and 20 controls. Plasma levels of mir-30e-3p and let-7f were associated with short disease-free survival and overall survival Overexpressed in cell lines for breast cancer, prostate cancer, glioblastoma, and lung cancer Underexpressed in cell lines for breast cancer, prostate cancer, glioblastoma, and lung cancer Underexpressed in cell lines for breast cancer, prostate cancer, glioblastoma, and lung cancer

Upregulated in lung carcinoma tissues and their corresponding normal lung tissues, high mir-21

Gao et al. (2010) expression and low mir-181a expression were associated with poor survival, independent of clinical covariates, including TNM staging, lymph note status

Downregulated in lung carcinoma tissues and their corresponding normal lung tissues, low level expression of mir-143 was significantly correlated with smoking status

Downregulated in lung carcinoma tissues and their corresponding normal lung tissues, high mir-21 expression and low mir-181a expression were associated with poor survival, independent of clinical covariates, including TNM staging, lymph note status

Upregulated in adenocarcinoma compared to squamous cell carcinoma Overexpressed in cell lines for breast cancer, prostate cancer, glioblastoma, and lung cancer
Upregulated in adenocarcinoma compared to squamous cell carcinoma Upregulated in adenocarcinoma compared to squamous cell carcinoma Upregulated in adenocarcinoma compared to squamous cell carcinoma Upregulated in adenocarcinoma compared to squamous cell carcinoma Downregulated in adenocarcinoma compared to squamous cell carcinoma Upregulated in adenocarcinoma compared to squamous cell carcinoma Upregulated in adenocarcinoma compared to squamous cell carcinoma Upregulated in adenocarcinoma compared to squamous cell carcinoma Upregulated in adenocarcinoma compared to squamous cell carcinoma Downregulated in adenocarcinoma compared to squamous cell carcinoma Upregulated in adenocarcinoma compared to squamous cell carcinoma Upregulated in adenocarcinoma compared to squamous cell carcinoma Upregulated in adenocarcinoma compared to squamous cell carcinoma Upregulated in adenocarcinoma compared to squamous cell carcinoma Upregulated in adenocarcinoma compared to squamous cell carcinoma Upregulated in adenocarcinoma compared to squamous cell carcinoma Upregulated in adenocarcinoma compared to squamous cell carcinoma Upregulated in adenocarcinoma compared to squamous cell carcinoma Upregulated in adenocarcinoma compared to squamous cell carcinoma Upregulated in adenocarcinoma compared to squamous cell carcinoma Upregulated in adenocarcinoma compared to squamous cell carcinoma Upregulated in adenocarcinoma compared to squamous cell carcinoma Upregulated in adenocarcinoma compared to squamous cell carcinoma Upregulated in adenocarcinoma compared to squamous cell carcinoma Upregulated in adenocarcinoma compared to squamous cell carcinoma Upregulated in adenocarcinoma compared to squamous cell carcinoma Upregulated in adenocarcinoma compared to squamous cell carcinoma Upregulated in adenocarcinoma compared to squamous cell carcinoma 


\section{Table A1 | Continued}

\section{miRNA}

miRNA function in lung neoplasia
Reference

Patnaik et al. (2010)
hsa-miR-29b

hsa-miR-491-5p

hsa-miR-19b

hsa-miR-107

hsa-miR-16

hsa-mir-129-5p

hsa-mir-194

hsa-mir-631

hsa-mir-200b

hsa-mir-585

hsa-mir-623

hsa-mir-617

hsa-mir-622

hsa-mir-638

hsa-mir-24

hsa-mir-141

hsa-mir-27b

hsa-mir-16

hsa-mir-21

hsa-mir-30c

hsa-mir-106a

hsa-mir-15b

hsa-mir-23b

hsa-mir-23b

hsa-mir-130a

hsa-mir-636

hsa-mir-593

hsa-mir-760

hsa-mir-139-3p

hsa-mir-345

hsa-mir-885-3p

hsa-mir-206

hsa-mir-516a-5p

hsa-mir-16-2*

hsa-mir-106a

hsa-mir-548c-3p

hsa-mir-127-3p

hsa-mir-1228*

hsa-mir-30b*

hsa-mir-376a

hsa-mir-34b*

hsa-mir-215

hsa-mir-183

hsa-mir-22*

hsa-mir-34a

hsa-mir-192

hsa-mir-30c- * $^{*}$

hsa-mir-21
Upregulated in adenocarcinoma compared to squamous cell carcinoma

Upregulated in adenocarcinoma compared to squamous cell carcinoma

Upregulated in adenocarcinoma compared to squamous cell carcinoma

Upregulated in adenocarcinoma compared to squamous cell carcinoma

Upregulated in adenocarcinoma compared to squamous cell carcinoma

Underexpressed in recurrence vs. No recurrence case groups of stage I NSCLC

Underexpressed in recurrence vs. No recurrence case groups of stage I NSCLC

Underexpressed in recurrence vs. No recurrence case groups of stage I NSCLC

Underexpressed in recurrence vs. No recurrence case groups of stage I NSCLC

Underexpressed in recurrence vs. No recurrence case groups of stage I NSCLC

Underexpressed in recurrence vs. No recurrence case groups of stage I NSCLC

Underexpressed in recurrence vs. No recurrence case groups of stage I NSCLC

Underexpressed in recurrence vs. No recurrence case groups of stage I NSCLC

Underexpressed in recurrence vs. No recurrence case groups of stage I NSCLC

Overexpressed in recurrence vs. No recurrence case groups of stage I NSCLC

Overexpressed in recurrence vs. No recurrence case groups of stage I NSCLC

Overexpressed in recurrence vs. No recurrence case groups of stage I NSCLC

Overexpressed in recurrence vs. No recurrence case groups of stage I NSCLC

Overexpressed in recurrence vs. No recurrence case groups of stage I NSCLC

Overexpressed in recurrence vs. No recurrence case groups of stage I NSCLC

Overexpressed in recurrence vs. No recurrence case groups of stage I NSCLC

Overexpressed in recurrence vs. No recurrence case groups of stage I NSCLC

Overexpressed in recurrence vs. No recurrence case groups of stage I NSCLC

Overexpressed in recurrence vs. No recurrence case groups of stage I NSCLC

Overexpressed in recurrence vs. No recurrence case groups of stage I NSCLC

Changed more than twofold by radiation doses of 20Gy

Changed more than twofold by radiation doses of $20 \mathrm{~Gy}$

Changed more than twofold by radiation doses of $20 \mathrm{~Gy}$

Changed more than twofold by radiation doses of $20 \mathrm{~Gy}$

Changed more than twofold by radiation doses of $20 \mathrm{~Gy}$ and $40 \mathrm{~Gy}$

Changed more than twofold by radiation doses of 20Gy and 40Gy

Changed more than twofold by radiation doses of 20Gy and 40Gy

Changed more than twofold by radiation doses of 20Gy and 40Gy

Changed more than twofold by radiation doses of 20Gy and 40Gy

Changed more than twofold by radiation doses of 20Gy and 40Gy

Changed more than twofold by radiation doses of 20Gy and 40Gy

Changed more than twofold by radiation doses of 20Gy and 40Gy

Changed more than twofold by radiation doses of $40 \mathrm{~Gy}$

Changed more than twofold by radiation doses of $40 \mathrm{~Gy}$

Changed more than twofold by radiation doses of $40 \mathrm{~Gy}$

Changed more than twofold by radiation doses of $40 \mathrm{~Gy}$

Changed more than twofold by radiation doses of $40 \mathrm{~Gy}$

Changed more than twofold by radiation doses of $40 \mathrm{~Gy}$

Changed more than twofold by radiation doses of $40 \mathrm{~Gy}$

Changed more than twofold by radiation doses of $40 \mathrm{~Gy}$

Changed more than twofold by radiation doses of $40 \mathrm{~Gy}$

Changed more than twofold by radiation doses of $40 \mathrm{~Gy}$

Mir-21 expression in the sputum specimens was significantly higher in cancer patients than

Xie et al. (2010) cancer-free individuals. overexpression of mir-21 showed highly discriminative receiver-operator characteristic $(\mathrm{ROC})$ curve profile, clearly distinguishing cancer patients from cancer-free subjects Detection of mir-21 expression produced $69.66 \%$ sensitivity and $100.00 \%$ specificity in diagnosis of lung cancer, as compared with $47.82 \%$ sensitivity and $100.00 \%$ specificity by sputum cytology
Shin et al. (2009) 


\section{Table A1 | Continued}

\section{miRNA}

hsa-mir-140-3p

hsa-mir-628-5p

hsa-mir-518f

hsa-mir-636

hsa-mir-301a

hsa-mir-34c

hsa-mir-224

hsa-mir-197

hsa-mir-205

hsa-mir-135b

hsa-mir-200b

hsa-mir-200c

hsa-mir-141

hsa-mir-182

hsa-mir-126

hsa-mir-200c

hsa-mir-141

hsa-mir-375

hsa-mir-7

hsa-mir-429

hsa-mir-200a

hsa-mir-370

hsa-mir-451

hsa-mir-195

hsa-mir-200b

hsa-mir-486-5p

hsa-mir-214

hsa-mir-382

hsa-mir-199a-5p

hsa-mis-210

hsa-mir-200c

hsa-mir-17-5p

hsa-mir-20a

hsa-mir-203

hsa-mir-125a

hsa-let-7e

hsa-mir-200a

hsa-mir-106b

hsa-mir-93

\section{miRNA function in lung neoplasia}

Reference

Expression of 13 miRNA genes predicts response to EGFR inhibition in cancer cell lines and tumors, and discriminates primary from metastatic tumors

Expression of 13 miRNA genes predicts response to EGFR inhibition in cancer cell lines and tumors, and discriminates primary from metastatic tumors

Expression of 13 miRNA genes predicts response to EGFR inhibition in cancer cell lines and tumors, and discriminates primary from metastatic tumors

Expression of 13 miRNA genes predicts response to EGFR inhibition in cancer cell lines and tumors, and discriminates primary from metastatic tumors

Expression of 13 miRNA genes predicts response to EGFR inhibition in cancer cell lines and tumors, and discriminates primary from metastatic tumors

Expression of 13 miRNA genes predicts response to EGFR inhibition in cancer cell lines and tumors, and discriminates primary from metastatic tumors

Expression of 13 miRNA genes predicts response to EGFR inhibition in cancer cell lines and tumors, and discriminates primary from metastatic tumors

Expression of 13 miRNA genes predicts response to EGFR inhibition in cancer cell lines and tumors, and discriminates primary from metastatic tumors

Expression of 13 miRNA genes predicts response to EGFR inhibition in cancer cell lines and tumors, and discriminates primary from metastatic tumors

Expression of 13 miRNA genes predicts response to EGFR inhibition in cancer cell lines and tumors, and discriminates primary from metastatic tumors

Expression of 13 miRNA genes predicts response to EGFR inhibition in cancer cell lines and tumors, and discriminates primary from metastatic tumors

Expression of 13 miRNA genes predicts response to EGFR inhibition in cancer cell lines and tumors, and discriminates primary from metastatic tumors

Expression of 13 miRNA genes predicts response to EGFR inhibition in cancer cell lines and tumors, and discriminates primary from metastatic tumors

Overexpressed in primary lung tumors vs. metastases to lung

Barshack et al. (2010)

Underexpressed in primary lung tumors vs. metastases to lung

Overexpressed in primary lung tumors vs. metastases to lung

Overexpressed in primary lung tumors vs. metastases to lung

Overexpressed in primary lung tumors vs. metastases to lung

Overexpressed in primary lung tumors vs. metastases to lung

Overexpressed in primary lung tumors vs. metastases to lung

Overexpressed in primary lung tumors vs. metastases to lung

Overexpressed in primary lung tumors vs. metastases to lung

Underexpressed in primary lung tumors vs. metastases to lung

Underexpressed in primary lung tumors vs. metastases to lung

Overexpressed in primary lung tumors vs. metastases to lung

Underexpressed in primary lung tumors vs. metastases to lung

Underexpressed in primary lung tumors vs. metastases to lung

Overexpressed in primary lung tumors vs. metastases to lung

Underexpressed in primary lung tumors vs. metastases to lung

Upregulated in lung SCC compared to normal tissue

Upregulated in lung SCC compared to normal tissue

Upregulated in lung SCC compared to normal tissue

Upregulated in lung SCC compared to normal tissue

Upregulated in lung SCC compared to normal tissue

Downregulated in lung SCC compared to normal tissue

Downregulated in lung SCC compared to normal tissue

Upregulated in lung SCC compared to normal tissue

Upregulated in lung SCC compared to normal tissue

Upregulated in lung SCC compared to normal tissue
Bryant et al. (2011)

Raponi et al. (2009) 
Table A1 | Continued

\section{miRNA}

hsa-mir-182

hsa-mir-183

hsa-mir-106a

hsa-mir-20b

hsa-mir-224

hsa-miR-126

hsa-miR-423-5p

hsa-let-7d

hsa-let-7i

hsa-miR-15a

hsa-miR-22

hsa-miR-98

hsa-miR-19a

hsa-miR-20b

hsa-miR-324-3p

hsa-miR-574-5p

hsa-miR-195

hsa-miR-25

hsa-let-7e

hsa-let-7c

hsa-let-7f

hsa-let-7a

hsa-let-7g

hsa-miR-140-3p

hsa-miR-339-5p

hsa-miR-361-5p

hsa-miR-1283

hsa-miR-18a*

hsa-miR-26b

hsa-miR-641

hsa-miR-662

hsa-miR-369-5p

hsa-miR-383

hsa-miR-636

hsa-miR-940

hsa-miR-26a

hsa-miR-92a

hsa-miR-328

hsa-let-7d*

hsa-miR-1224-3p

hsa-miR-513b

hsa-miR-93*

hsa-miR-675
miRNA function in lung neoplasia

Reference

Upregulated in lung SCC compared to normal tissue Upregulated in lung SCC compared to normal tissue Upregulated in lung SCC compared to normal tissue Upregulated in lung SCC compared to normal tissue Upregulated in lung SCC compared to normal tissue Downregulated in NSCLC blood compared to normal blood Upregulated in NSCLC blood compared to normal blood Downregulated in NSCLC blood compared to normal blood Downregulated in NSCLC blood compared to normal blood Downregulated in NSCLC blood compared to normal blood Upregulated in NSCLC blood compared to normal blood Downregulated in NSCLC blood compared to normal blood Upregulated in NSCLC blood compared to normal blood Downregulated in NSCLC blood compared to normal blood Upregulated in NSCLC blood compared to normal blood Upregulated in NSCLC blood compared to normal blood Downregulated in NSCLC blood compared to normal blood Upregulated in NSCLC blood compared to normal blood Downregulated in NSCLC blood compared to normal blood Downregulated in NSCLC blood compared to normal blood Downregulated in NSCLC blood compared to normal blood Downregulated in NSCLC blood compared to normal blood Downregulated in NSCLC blood compared to normal blood Upregulated in NSCLC blood compared to normal blood Upregulated in NSCLC blood compared to normal blood Upregulated in NSCLC blood compared to normal blood Downregulated in NSCLC blood compared to normal blood Upregulated in NSCLC blood compared to normal blood Downregulated in NSCLC blood compared to normal blood Downregulated in lung cancer vs. COPD Upregulated in lung cancer vs. COPD Downregulated in lung cancer vs. COPD Downregulated in lung cancer vs. COPD Upregulated in lung cancer vs. COPD Upregulated in lung cancer vs. COPD Downregulated in lung cancer vs. COPD Upregulated in lung cancer vs. COPD Upregulated in lung cancer vs. COPD Upregulated in lung cancer vs. COPD Upregulated in lung cancer vs. COPD Downregulated in lung cancer vs. COPD Upregulated in lung cancer vs. COPD Upregulated in lung cancer vs. COPD

This table only includes a selection of available publications. 


\section{REFERENCES}

Arora, H., Qureshi, R., Jin, S., Park, A. K., and Park, W. Y. (2011a). miR9 and let-7g enhance the sensitivity to ionizing radiation by suppression of NFkappaB1. Exp. Mol. Med. 43, 298-304.

Arora, H., Qureshi, R., Park, A. K., and Park, W. Y. (2011b). Coordinated regulation of ATF2 by miR$26 \mathrm{~b}$ in gamma-irradiated lung cancer cells. PLOS ONE 6, e23802. doi:10.1371/journal.pone.0023802

Barshack, I., Lithwick-Yanai, G., Afek, A., Rosenblatt, K., Tabibian-Keissar, H., Zepeniuk, M., Cohen, L., Dan, H., Zion, O., Strenov, Y., PolakCharcon, S., and Perelman, M. (2010). MicroRNA expression differentiates between primary lung tumors and metastases to the lung. Pathol. Res. Pract. 206, 578-584.

Bryant, J. L., Britson, J., Balko, J. M., Willian, M., Timmons, R., Frolov, A., and Black, E. P. (2011). A microRNA gene expression signature predicts response to erlotinib in epithelial cancer cell lines and targets EMT. Br. J. Cancer. doi: 10.1038/bjc.2011.465. [Epub ahead of print].

Calin, G. A., Sevignani, C., Dumitru, C. D., Hyslop, T., Noch, E., Yendamuri, S., Shimizu, M., Rattan, S., Bullrich, F., Negrini, M., and Croce, C. M. (2004). Human microRNA genes are frequently located at fragile sites and genomic regions involved in cancers. Proc. Natl. Acad. Sci. U.S.A. 101, 2999-3004.

Cao, G., Huang, B., Liu, Z., Zhang, J., Xu, H., Xia, W., Li, J., Li, S., Chen, L., Ding, H., Zhao, Q., Fan, M., Shen, B., and Shao, N. (2010). Intronic miR-301 feedback regulates its host gene, ska2, in A549 cells by targeting MEOX2 to affect ERK/CREB pathways. Biochem. Biophys. Res. Commun. 396, 978-982.

Chen, L. P., Lai, Y. D., Li, D. C., Zhu, X. N., Yang, P., Li, W. X., Zhu, W., Zhao, J., Li, X. D., Xiao, Y. M., Zhang, Y., Xing, X. M., Wang, Q., Zhang, B., Lin, Y. C., Zeng, J. L., Zhang, S. X., Liu, C. X., Li, Z. F., Zeng, X. W., Lin, Z. N., Zhuang, Z. X., and Chen, W. (2011a). Alpha4 is highly expressed in carcinogen-transformed human cells and primary human cancers. Oncogene 30, 2943-2953.

Chen, W. S., Hou, J. N., Guo, Y. B., Yang, H. L., Xie, C. M., Lin, Y. C., and She, Z. G. (2011b). Bostrycin inhibits proliferation of human lung carcinoma A549 cells via downregulation of the PI3K/Akt pathway. J. Exp. Clin. Cancer Res. 30, 17.

Chen, X., Hu, Z., Wang, W., Ba, Y., Ma, L., Zhang, C., Wang, C., Ren, Z., Zhao,
Y., Wu, S., Zhuang, R., Zhang, Y., Hu, H., Liu, C., Xu, L., Wang, J., Shen, H., Zhang, J., Zen, K., and Zhang, C. Y. (2011c). Identification of ten serum microRNAs from a genome-wide serum microRNA expression profile as novel noninvasive biomarkers for nonsmall cell lung cancer diagnosis. Int. J. Cancer. doi: 10.1002/ijc.26177. [Epub ahead of print].

Chin, L. J., Ratner, E., Leng, S., Zhai, R., Nallur, S., Babar, I., Muller, R. U., Straka, E., Su, L., Burki, E. A., Crowell, R. E., Patel, R., Kulkarni, T., Homer, R., Zelterman, D., Kidd, K. K., Zhu, Y., Christiani, D. C., Belinsky, S. A., Slack, F. J., and Weidhaas, J. B. (2008). A SNP in a let-7 microRNA complementary site in the KRAS 3' untranslated region increases non-small cell lung cancer risk. Cancer Res. 68, 8535-8540.

Cho, W. C., Chow, A. S., and Au, J. S. (2011). MiR-145 inhibits cell proliferation of human lung adenocarcinoma by targeting EGFR and NUDT1. RNA Biol 8, 125-131.

Chu, H., Wang, M., Shi, D., Ma, L., Zhang, Z., Tong, N., Huo, X., Wang, W., Luo, D., and Gao, Y. (2011). Hsa-miR-196a2 Rs11614913 polymorphism contributes to cancer susceptibility: evidence from 15 case-control studies. PLoS ONE 6, e18108. doi:10.1371/journal.pone.0018108

Crawford, M., Batte, K., Yu, L., Wu, X., Nuovo, G. J., Marsh, C. B., Otterson, G. A., and Nana-Sinkam, S. P. (2009). MicroRNA 133B targets pro-survival molecules MCL1 and BCL2L2 in lung cancer. Biochem. Biophys. Res. Commun. 388, 483-489.

Crawford, M., Brawner, E., Batte, K., Yu, L., Hunter, M. G., Otterson, G. A., Nuovo, G., Marsh, C. B., and Nana-Sinkam, S. P. (2008). MicroRNA-126 inhibits invasion in non-small cell lung carcinoma cell lines. Biochem. Biophys. Res. Commun. 373, 607-612.

Du, L., Schageman, J. J., Irnov, Girard, L., Hammond, S. M., Minna, J. D., Gazdar, A. F., and Pertsemlidis, A. (2010). MicroRNA expression distinguishes SCLC from NSCLC lung tumor cells and suggests a possible pathological relationship between SCLCs and NSCLCs. J. Exp. Clin. Cancer Res. 29, 75.

Du, L., Schageman, J. J., Subauste, M. C., Saber, B., Hammond, S. M., Prudkin, L., Wistuba, II, Ji, L., Roth, J. A., Minna, J. D., and Pertsemlidis, A. (2009). miR-93, miR-98, and miR197 regulate expression of tumor suppressor gene FUS1. Mol. Cancer Res. 7, 1234-1243.

Duan, W., Gao, L., Wu, X., Wang, L., Nana-Sinkam, S. P., Otterson, G. A., and Villalona-Calero, M. A. (2010). MicroRNA-34a is an important component of PRIMA1-induced apoptotic network in human lung cancer cells. Int. J. Cancer 127, 313-320.

Ebi, H., Sato, T., Sugito, N., Hosono, Y., Yatabe, Y., Matsuyama, Y., Yamaguchi, T., Osada, H., Suzuki, M., and Takahashi, T. (2009). Counterbalance between RB inactivation and miR-17-92 overexpression in reactive oxygen species and DNA damage induction in lung cancers. Oncogene 28, 3371-3379.

Fabbri, M., Garzon, R., Cimmino, A., Liu, Z., Zanesi, N., Callegari, E., Liu, S., Alder, H., Costinean, S., Fernandez-Cymering, C., Volinia, S., Guler, G., Morrison, C. D., Chan, K. K., Marcucci, G., Calin, G. A., Huebner, K., and Croce, C. M. (2007). MicroRNA-29 family reverts aberrant methylation in lung cancer by targeting DNA methyltransferases $3 \mathrm{~A}$ and $3 \mathrm{~B}$. Proc. Natl. Acad. Sci. U.S.A. 104 15805-15810.

Gallardo, E., Navarro, A., Vinolas, N. Marrades, R. M., Diaz, T., Gel, B., Quera, A., Bandres, E., GarciaFoncillas, J., Ramirez, J., and Monzo, M. (2009). miR-34a as a prognostic marker of relapse in surgically resected non-small-cell lung cancer. Carcinogenesis 30, 1903-1909.

Gao, W., Yu, Y., Cao, H., Shen, H., Li, X., Pan, S., and Shu, Y. (2010). Deregulated expression of miR-21, miR-143 and miR-181a in non small cell lung cancer is related to clinicopathologic characteristics or patient prognosis. Biomed. Pharmacother. 64, 399-408.

Guan, H., Zhang, P., Liu, C., Zhang, J., Huang, Z., Chen, W., Chen, Z., Ni, N., Liu, Q., and Jiang, A. (2011). Characterization and functional analysis of the human microRNA let-7a2 promoter in lung cancer A549 cell lines. Mol. Biol. Rep. 38, 5327-5334.

Hanoun, N., Delpu, Y., Suriawinata, A. A., Bournet, B., Bureau, C., Selves, J., Tsongalis, G. J., Dufresne, M., Buscail, L., Cordelier, P., and Torrisani, J. (2010). The silencing of microRNA 148a production by DNA hypermethylation is an early event in pancreatic carcinogenesis. Clin. Chem. 56, 1107-1118.

Hayashita, Y., Osada, H., Tatematsu, Y., Yamada, H., Yanagisawa, K., Tomida, S., Yatabe, Y., Kawahara, K., Sekido,
Y., and Takahashi, T. (2005). A polycistronic microRNA cluster, miR-1792 , is overexpressed in human lung cancers and enhances cell proliferation. Cancer Res. 65, 9628-9632.

Hu, Z., Chen, X., Zhao, Y., Tian, T., Jin, G., Shu, Y., Chen, Y., Xu, L., Zen, K., Zhang, C., and Shen, H. (2010). Serum microRNA signatures identified in a genome-wide serum microRNA expression profiling predict survival of non-small-cell lung cancer. J. Clin. Oncol. 28, 1721-1726.

Jeong, S. H., Wu, H. G., and Park, W. Y. (2009). LIN28B confers radioresistance through the posttranscriptional control of KRAS. Exp. Mol. Med. 41, 912-918.

Jiang, L., Huang, Q., Chang, J., Wang, E., and Qiu, X. (2011). MicroRNA HSA-miR-125a-5p induces apoptosis by activating p53 in lung cancer cells. Exp. Lung Res. 37, 387-398.

Keller, A., Leidinger, P., Borries, A., Wendschlag, A., Wucherpfennig, F., Scheffler, M., Huwer, H., Lenhof, H. P., and Meese, E. (2009). miRNAs in lung cancer - studying complex fingerprints in patient's blood cells by microarray experiments. BMC Cancer 9, 353. doi:10.1186/1471-2407-9-353

Landi, M. T., Zhao, Y., Rotunno, M., Koshiol, J., Liu, H., Bergen, A. W., Rubagotti, M., Goldstein, A. M., Linnoila, I., Marincola, F. M., Tucker, M. A., Bertazzi, P. A., Pesatori, A. C., Caporaso, N. E., McShane, L. M., and Wang, E. (2010). MicroRNA expression differentiates histology and predicts survival of lung cancer. Clin. Cancer Res. 16, 430-441.

Lebanony, D., Benjamin, H., Gilad, S., Ezagouri, M., Dov, A., Ashkenazi, K., Gefen, N., Izraeli, S., Rechavi, G., Pass, H., Nonaka, D., Li, J., Spector, Y., Rosenfeld, N., Chajut, A., Cohen, D., Aharonov, R., and Mansukhani, M. (2009). Diagnostic assay based on hsa-miR-205 expression distinguishes squamous from nonsquamous non-small-cell lung carcinoma. J. Clin. Oncol. 27, 2030-2037.

Lee, J., Li, Z., Brower-Sinning, R., and John, B. (2007). Regulatory circuit of human microRNA biogenesis. PLoS Comput. Biol. 3, e67. doi:10.1371/journal.pcbi.0030067

Leidinger, P., Keller, A., Borries, A., Huwer, H., Rohling, M., Huebers, J., Lenhof, H. P., and Meese, E. (2011). Specific peripheral miRNA profiles for distinguishing lung cancer from COPD. Lung Cancer 74, 41-47.

Li, Y. J., Zhang, Y. X., Wang, P. Y., Chi, Y. L., Zhang, C., Ma, Y., Lv, C. J., and Xie, S. Y. (2011). Regression of A549 
lung cancer tumors by anti-miR-150 vector. Oncol. Rep. 27, 129-134.

Liu, B., Peng, X. C., Zheng, X. L., Wang, J., and Qin, Y. W. (2009a). MiR-126 restoration down-regulate VEGF and inhibit the growth of lung cancer cell lines in vitro and in vivo. Lung Cancer 66, 169-175.

Liu, X., Sempere, L. F., Galimberti, F., Freemantle, S. J., Black, C., Dragnev, K. H., Ma, Y., Fiering, S., Memoli, V., Li, H., DiRenzo, J., Korc, M., Cole, C. N., Bak, M., Kauppinen, S., and Dmitrovsky, E. (2009b). Uncovering growth-suppressive MicroRNAs in lung cancer. Clin. Cancer Res. 15, 1177-1183.

Liu, X., Sempere, L. F., Ouyang, H., Memoli, V. A., Andrew, A. S., Luo, Y., Demidenko, E., Korc, M., Shi, W., Preis, M., Dragnev, K. H., Li, H., Direnzo, J., Bak, M., Freemantle, S. J., Kauppinen, S., and Dmitrovsky, E. (2010). MicroRNA-31 functions as an oncogenic microRNA in mouse and human lung cancer cells by repressing specific tumor suppressors. J. Clin. Invest. 120, 1298-1309.

Liu, X. G., Zhu, W. Y., Huang, Y. Y., Ma, L. N., Zhou, S. Q., Wang, Y. K., Zeng, F., Zhou, J. H., and Zhang, Y. K. (2011). High expression of serum miR-2 1 and tumor miR-200c associated with poor prognosis in patients with lung cancer. Med. Oncol. PMID: 21516486. [Epub ahead of print].

Nasser, M. W., Datta, J., Nuovo, G., Kutay, H., Motiwala, T., Majumder, S., Wang, B., Suster, S., Jacob, S. T., and Ghoshal, K. (2008). Downregulation of micro-RNA-1 (miR1) in lung cancer. Suppression of tumorigenic property of lung cancer cells and their sensitization to doxorubicin-induced apoptosis by miR-1. J. Biol. Chem. 283, 33394-33405.

Navon, R., Wang, H., Steinfeld, I., Tsalenko, A., Ben-Dor, A., and Yakhini, Z. (2009). Novel rank-based statistical methods reveal microRNAs with differential expression in multiple cancer types. PLoS ONE 4, e8003. doi:10.1371/journal.pone.0008003

Nishikawa, E., Osada, H., Okazaki, Y., Arima, C., Tomida, S., Tatematsu, Y., Taguchi, A., Shimada, Y., Yanagisawa, K., Yatabe, Y., Toyokuni, S., Sekido, Y., and Takahashi, T. (2011). miR375 is activated by ASH1 and inhibits YAP1 in a lineage-dependent manner in lung cancer. Cancer Res. 71, 6165-6173.

Park, S., Minai-Tehrani, A., Xu, C. X., Chang, S. H., Woo, M. A., Noh, M. S., Lee, E. S., Lim, H. T., An, G. H., Lee, K. H., Sung, H. J., Beck, G. R., and Cho, M. H. (2011). Suppression of A549 lung cancer cell migration by precursor let-7g microRNA. Mol. Med. Rep. 3, 1007-1013.

Patnaik, S. K., Kannisto, E., Knudsen, S., and Yendamuri, S. (2010). Evaluation of microRNA expression profiles that may predict recurrence of localized stage I non-small cell lung cancer after surgical resection. Cancer Res. 70, 36-45.

Patnaik, S. K., Kannisto, E., Mallick, R., and Yendamuri, S. (2011). Overexpression of the lung cancerprognostic miR-146b microRNAs has a minimal and negative effect on the malignant phenotype of A549 lung cancer cells. PLoS ONE 6, e22379. doi:10.1371/journal.pone.0022379

Qin, A., Zhou, Y., Sheng, M., Fei, G., Ren, T., and Xu, L. (2011). Effects of microRNA-155 on the growth of human lung cancer cell line 95D in vitro. Zhongguo Fei Ai Za Zhi 14, 575-580.

Raponi, M., Dossey, L., Jatkoe, T., Wu, X., Chen, G., Fan, H., and Beer, D. G. (2009). MicroRNA classifiers for predicting prognosis of squamous cell lung cancer. Cancer Res. 69, 5776-5783.

Roa, W., Brunet, B., Guo, L., Amanie, J., Fairchild, A., Gabos, Z., Nijjar, T., Scrimger, R., Yee, D., and Xing, J. (2010). Identification of a new microRNA expression profile as a potential cancer screening tool. Clin. Invest. Med. 33, E124.

Seike, M., Goto, A., Okano, T., Bowman, E. D., Schetter, A. J., Horikawa, I., Mathe, E. A., Jen, J., Yang, P., Sugimura, H., Gemma, A., Kudoh, S., Croce, C. M., and Harris, C. C. (2009). MiR-21 is an EGFR-regulated anti-apoptotic factor in lung cancer in never-smokers. Proc. Natl. Acad. Sci. U.S.A. 106, 12085-12090.

Sempere, L. F., Liu, X., and Dmitrovsky, E. (2009). Tumor-suppressive microRNAs in Lung cancer: diagnostic and therapeutic opportunities. Sci. World J. 9, 626-628.

Shin, S., Cha, H. J., Lee, E. M., Lee, S. J., Seo, S. K., Jin, H. O., Park, I. C., Jin, Y. W., and An, S. (2009). Alteration of miRNA profiles by ionizing radiation in A549 human non-small cell lung cancer cells. Int. J. Oncol.35, 81-86.

Silva, J., Garcia, V., Zaballos, A., Provencio, M., Lombardia, L., Almonacid, L., Garcia, J. M., Dominguez, G., Pena, C., Diaz, R., Herrera, M., Varela, A., and Bonilla, F.
(2011). Vesicle-related microRNAs in plasma of nonsmall cell lung cancer patients and correlation with survival. Eur. Respir. J. 37, 617-623.

Sun, Y., Fang, R., Li, C., Li, L., Li, F., Ye, X., and Chen, H. (2010). Hsa-mir182 suppresses lung tumorigenesis through down regulation of RGS17 expression in vitro. Biochem. Biophys. Res. Commun. 396, 501-507.

Takahashi, Y., Forrest, A. R., Maeno, E., Hashimoto, T., Daub, C. O., and Yasuda, J. (2009). MiR-107 and MiR185 can induce cell cycle arrest in human non small cell lung cancer cell lines. PLoS ONE 4, e6677. doi:10.1371/journal.pone.0006677

Takamizawa, J., Konishi, H., Yanagisawa, K., Tomida, S., Osada, H., Endoh, H., Harano, T., Yatabe, Y., Nagino, M., Nimura, Y., Mitsudomi, T., and Takahashi, T. (2004). Reduced expression of the let-7 microRNAs in human lung cancers in association with shortened postoperative survival. Cancer Res. 64, 3753-3756.

Thu, K. L., Chari, R., Lockwood, W. W., Lam, S., and Lam, W. L. (2011). miR101 DNA copy loss is a prominent subtype specific event in lung cancer. J. Thorac. Oncol. 6, 1594-1598.

Tian, T., Shu, Y., Chen, J., Hu, Z., Xu, L., Jin, G., Liang, J., Liu, P., Zhou, X., Miao, R., Ma, H., Chen, Y., and Shen, H. (2009). A functional genetic variant in microRNA-196a 2 is associated with increased susceptibility of lung cancer in Chinese. Cancer Epidemiol. Biomarkers Prev. 18, 1183-1187.

Volinia, S., Calin, G. A., Liu, C. G., Ambs, S., Cimmino, A., Petrocca, F., Visone, R., Iorio, M., Roldo, C., Ferracin, M., Prueitt, R. L., Yanaihara, N., Lanza, G., Scarpa, A., Vecchione, A., Negrini, M., Harris, C. C., and Croce, C. M. (2006). A microRNA expression signature of human solid tumors defines cancer gene targets. Proc. Natl. Acad. Sci. U.S.A. 103, 2257-2261.

Vosa, U., Vooder, T., Kolde, R., Fischer, K., Valk, K., Tonisson, N., Roosipuu, R., Vilo, J., Metspalu, A., and Annilo, T. (2011). Identification of miR-374a as a prognostic marker for survival in patients with early-stage nonsmall cell lung cancer. Genes Chromosomes Cancer 50, 812-822.

Wang, G., Mao, W., and Zheng, S. (2008). MicroRNA-183 regulates Ezrin expression in lung cancer cells. FEBS Lett. 582, 3663-3668.

Wang, X., Ling, C., Bai, Y., and Zhao, J. (2010). MicroRNA-206 is associated with invasion and metastasis of lung cancer. Anat. Rec. (Hoboken) 294, 88-92.
Wang, X. C., Du, L. Q., Tian, L. L., Wu, H. L., Jiang, X. Y., Zhang, H., Li, D. G., Wang, Y. Y., Wu, H. Y., She, Y., Liu, Q. F., Fan, F. Y., and Meng, A. M. (2011a). Expression and function of miRNA in postoperative radiotherapy sensitive and resistant patients of non-small cell lung cancer. Lung Cancer 72, 92-99.

Wang, Z., Yang, J., Fisher, T., Xiao, H., Jiang, Y., and Yang, C. (2011b). Akt activation is responsible for enhanced migratory and invasive behavior of arsenic-transformed human bronchial epithelial cells. Environ. Health Perspect. doi: 10.1289/ehp.1104061. [Epub ahead of print].

Weiss, G. J., Bemis, L. T., Nakajima, E., Sugita, M., Birks, D. K., Robinson, W. A., Varella-Garcia, M., Bunn, P. A. Jr., Haney, J., Helfrich, B. A., Kato, H., Hirsch, F. R., and Franklin, W. A. (2008). EGFR regulation by microRNA in lung cancer: correlation with clinical response and survival to gefitinib and EGFR expression in cell lines. Ann. Oncol. 19, 1053-1059.

Wiggins, J. F., Ruffino, L., Kelnar, K., Omotola, M., Patrawala, L., Brown, D., and Bader, A. G. (2010). Development of a lung cancer therapeutic based on the tumor suppressor microRNA-34. Cancer Res. 70, 5923-5930.

Xie, Y., Todd, N. W., Liu, Z., Zhan, M., Fang, H., Peng, H., Alattar, M., Deepak, J., Stass, S. A., and Jiang, F. (2010). Altered miRNA expression in sputum for diagnosis of nonsmall cell lung cancer. Lung Cancer 67, 170-176.

Yanaihara, N., Caplen, N., Bowman, E., Seike, M., Kumamoto, K., Yi, M., Stephens, R. M., Okamoto, A., Yokota, J., Tanaka, T., Calin, G. A., Liu, C. G., Croce, C. M., and Harris, C. C. (2006). Unique microRNA molecular profiles in lung cancer diagnosis and prognosis. Cancer Cell 9, 189-198.

Yang, Y., Ahn, Y. H., Gibbons, D. L., Zang, Y., Lin, W., Thilaganathan, N., Alvarez, C. A., Moreira, D. C., Creighton, C. J., Gregory, P. A., Goodall, G. J., and Kurie, J. M. (2011). The Notch ligand Jagged2 promotes lung adenocarcinoma metastasis through a miR200-dependent pathway in mice. J. Clin. Invest. 121, 1373-1385.

Yang, Y., Li, X., Yang, Q., Wang, X., Zhou, Y., Jiang, T., Ma, Q., and Wang, Y. J. (2010). The role of microRNA in human lung squamous cell carcinoma. Cancer Genet. Cytogenet. 200, 127-133. 
Yin, R., Zhang, S., Wu, Y., Fan, X., Jiang, F., Zhang, Z., Feng, D., Guo, X., and $\mathrm{Xu}, \mathrm{L}$. (2011). microRNA-145 suppresses lung adenocarcinomainitiating cell proliferation by targeting OCT4. Oncol. Rep. 25, 1747-1754.

Zhang, J., Zhang, T., Ti, X., Shi, J., Wu, C., Ren, X., and Yin, H. (2010a). Curcumin promotes apoptosis in A549/DDP multidrugresistant human lung adenocarcinoma cells through an miRNA signaling pathway. Biochem. Biophys. Res. Commun. 399, 1-6.

Zhang, J. G., Wang, J. J., Zhao, F., Liu, Q., Jiang, K., and Yang, G. H. (2010b). MicroRNA-21 (miR-21) represses tumor suppressor PTEN and promotes growth and invasion in non-small cell lung cancer (NSCLC). Clin. Chim. Acta 411, 846-852.

Zhang, L., Liu, T., Huang, Y., and Liu, J. (2011a). microRNA-182 inhibits the proliferation and invasion of human lung adenocarcinoma cells through its effect on human cortical actinassociated protein. Int. J. Mol. Med. 28, 381-388.

Zhang, S., Wu, Y., Feng, D., Zhang, Z., Jiang, F., Yin, R., and Xu, L. (2011b). miR-145 inhibits lung adenocarcinoma stem cells proliferation by targeting OCT4 gene. Zhongguo Fei Ai Za Zhi 14, 317-322.

Zhang, Y., Ma, T., Yang, S., Xia, M., Xu, J., An, H., Yang, Y., and Li, S. (2011c).
High-mobility group Al proteins enhance the expression of the oncogenic miR-222 in lung cancer cells. Mol. Cell. Biochem. 357, 363-371.

Zheng, D., Haddadin, S., Wang, Y., Gu, L. Q., Perry, M. C., Freter, C. E., and Wang, M. X. (2011). Plasma microRNAs as novel biomarkers for early detection of lung cancer. Int. J. Clin. Exp. Pathol. 4, 575-586.

Zhong, M., Ma, X., Sun, C., and Chen, L. (2010). MicroRNAs reduce tumor growth and contribute to enhance cytotoxicity induced by gefitinib in non-small cell lung cancer. Chem. Biol. Interact. 184, 431-438.

Zhu, W., Liu, X., He, J., Chen, D., Hunag, Y., and Zhang, Y. K.
(2011). Overexpression of members of the microRNA-183 family is a risk factor for lung cancer: a case control study. BMC Cancer 11, 393. doi:10.1186/1471-240711-393

Zhu, W., Shan, X., Wang, T., Shu, Y., and Liu, P. (2010a). miR-181b modulates multidrug resistance by targeting BCL2 in human cancer cell lines. Int. J. Cancer 127, 2520-2529.

Zhu, W., Zhu, D., Lu, S., Wang, T., Wang, J., Jiang, B., Shu, Y., and Liu, P. (2010b). miR-497 modulates multidrug resistance of human cancer cell lines by targeting BCL2. Med. Oncol. doi: 10.1007/s12032010-9797-4. [Epub ahead of print]. 